\title{
A Multi-Sided Platform Keystone Ecosystem for Making Money Built on Open Source Components
}

\author{
by \\ Leonard De Baets
}

A thesis submitted to the Faculty of Graduate and Postdoctoral Affairs in partial fulfillment of the requirements for the degree of

Master of Applied Science

in

Technology Innovation Management

Department of Systems and Computer Engineering

Carleton University

Ottawa, Ontario

(C) Copyright 2012 Leonard De Baets 
Library and Archives

Canada

Published Heritage

Branch

395 Wellington Street

Ottawa ON K1A ON4

Canada
Bibliothèque et

Archives Canada

Direction du

Patrimoine de l'édition

395 , rue Wellington

Ottawa ON K1A ON4

Canada
Your file Votre référence

ISBN: 978-0-494-93480-7

Our file Notre référence

ISBN: 978-0-494-93480-7
NOTICE:

The author has granted a nonexclusive license allowing Library and Archives Canada to reproduce, publish, archive, preserve, conserve, communicate to the public by telecommunication or on the Internet, loan, distrbute and sell theses worldwide, for commercial or noncommercial purposes, in microform, paper, electronic and/or any other formats.

The author retains copyright ownership and moral rights in this thesis. Neither the thesis nor substantial extracts from it may be printed or otherwise reproduced without the author's permission.
AVIS:

L'auteur a accordé une licence non exclusive permettant à la Bibliothèque et Archives Canada de reproduire, publier, archiver, sauvegarder, conserver, transmettre au public par télécommunication ou par l'Internet, prêter, distribuer et vendre des thèses partout dans le monde, à des fins commerciales ou autres, sur support microforme, papier, électronique et/ou autres formats.

L'auteur conserve la propriété du droit d'auteur et des droits moraux qui protege cette thèse. $\mathrm{Ni}$ la thèse ni des extraits substantiels de celle-ci ne doivent être imprimés ou autrement reproduits sans son autorisation.
In compliance with the Canadian Privacy Act some supporting forms may have been removed from this thesis.

While these forms may be included in the document page count, their removal does not represent any loss of content from the thesis.
Conformément à la loi canadienne sur la protection de la vie privée, quelques formulaires secondaires ont été enlevés de cette thèse.

Bien que ces formulaires aient inclus dans la pagination, il n'y aura aucun contenu manquant. 


\section{Abstract}

This research examines the construction of the software platform that enables a keystone ecosystem operating as a Multi-Sided Platform (MSP) to make money through enabling deal-making. The results of the research are relevant to keystone owners, operators, and entrepreneurial companies who need to generate revenue. The design of the platform embodies a MSP business model environment instead of the typical single-sided company business model environment. An open source Customer Relationship Management (CRM) system was used to construct the software package. The software enables players of different types to collaboratively develop and close deals methodically and efficiently. The software is designed to enable the keystone owner(s) to monitor and manage the health of the ecosystem. 


\section{Acknowledgements}

I wish to thank Tony Bailetti for his guidance and teaching, and all the professors and fellow students in the TIM program who made it a truly collaborative platform for learning. I am most grateful to my wife, Monique, and daughters Camille, Emily, and Christine for their love and support. 


\section{Table of Contents}

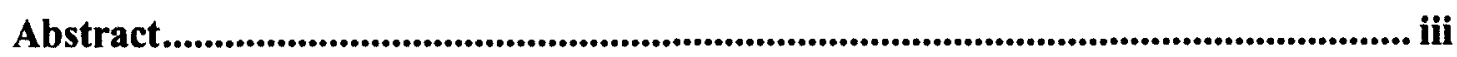

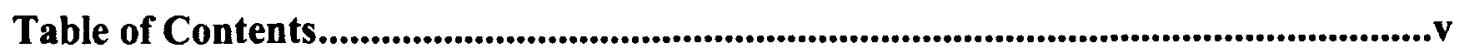

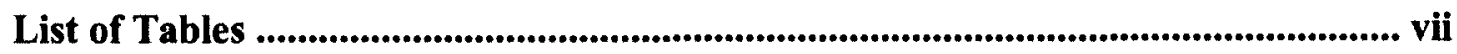

List of Illustrations .............................................................................................. viii

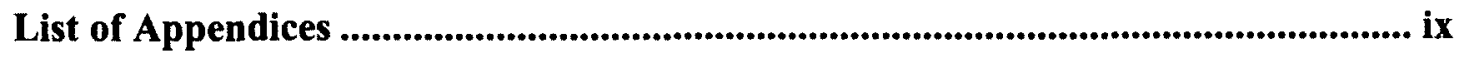

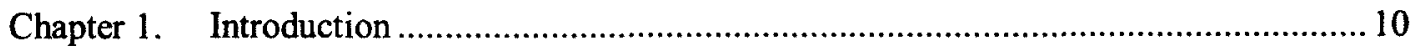

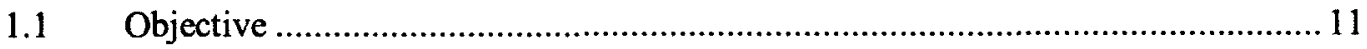

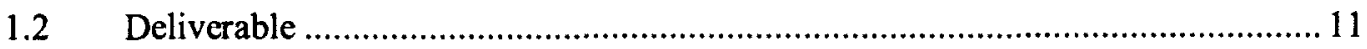

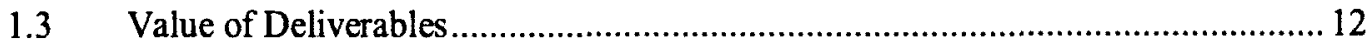

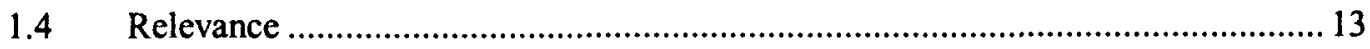

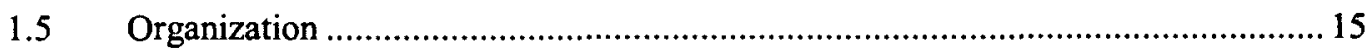

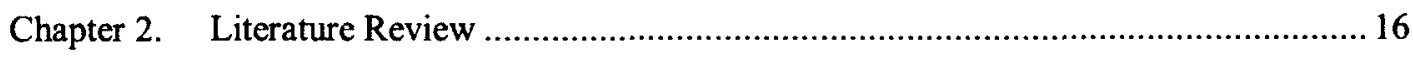

2.1 Customer Relationship Management ............................................................ 16

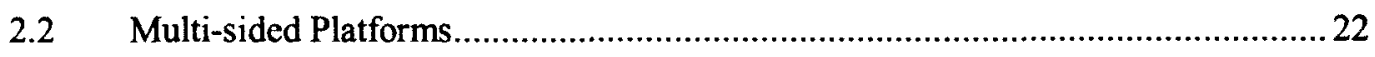

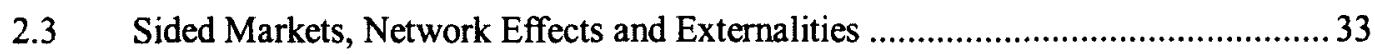

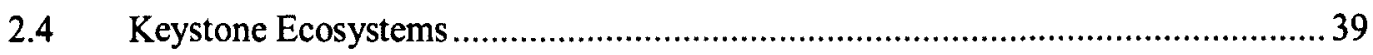

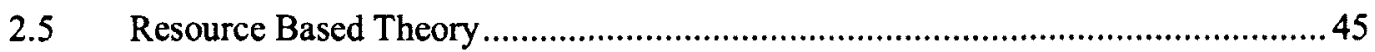

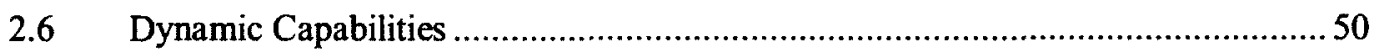

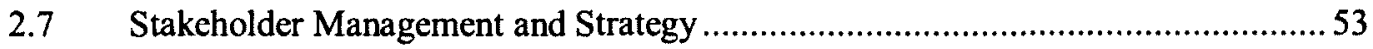

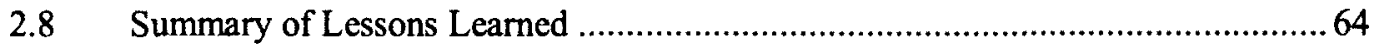

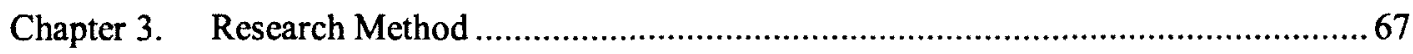

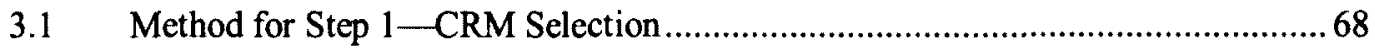

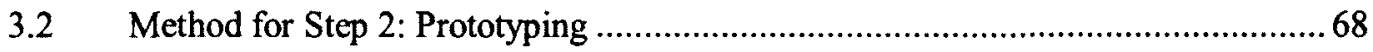


3.3 Method for Step 3: Production Quality …....................................................... 70

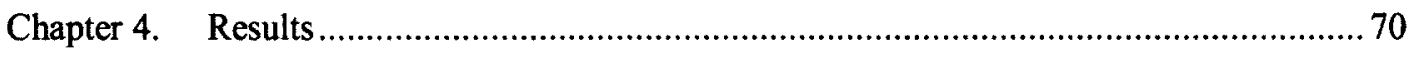

4.1 Outcome of Step 1 - Open Source CRM Selection ......................................... 70

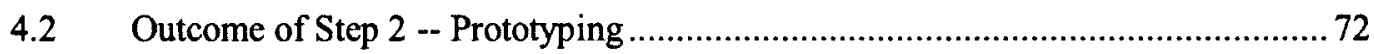

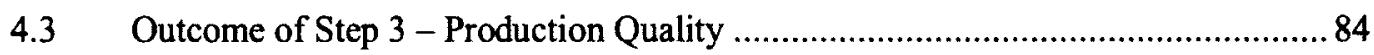

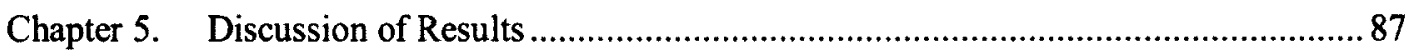

Chapter 6. Conclusion, Limitations, Suggestions for Future Research .............................. 94

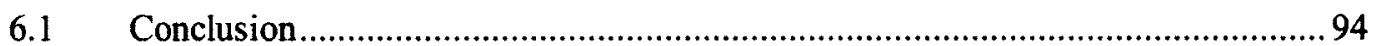

6.2 Limitations and Opportunities for Future Research ....................................... 97

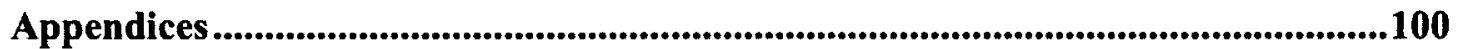

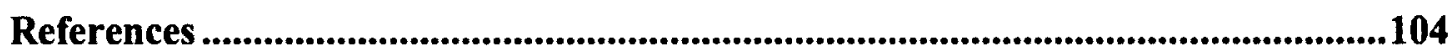




\section{List of Tables}

Table 1 -- Stakeholder Attributes to Salience Type Mappings ....................................55

Table 2 - Outline of basic steps to achieve Deliverables .......................................67

Table 3 - Business process support for a keystone ecosystem with Deal-Making...........79 


\section{List of Illustrations}

Figure 1 -- CRM Strategic Framework (Payne and Frow 2005).....................................18

Figure 2 - Differences between MSPs, Re-Sellers, and Input Suppliers ..........................26

Figure 3 -- Single 'model A' company sales in a typical CRM system ............................73

Figure 4 - Minimum Value Platform of a MSP keystone ecosystem with Deal-Making.74

Figure 5 -- State-Machine for Keystone Deal-Making.....................................................76

Figure 6 -- Deal Stakes as association objects associating company members to deals. ..83

Figure 7 -- Traditional 'model A' versus Keystone 'model C' Business Models..............101 


\section{List of Appendices}

Appendix A......................................................... 100

A.1 Business Models A and C for Revenue Growth........................ 100

Appendix B................................................................ 101

B.1 Bugs and Issues from the last two prototypes ...................... 101 


\section{Chapter 1. Introduction}

Customer Relationship Management (CRM) tools, systems, and processes have been used extensively for more than a decade. They are used by companies to manage relationships with customers at various touch-points of interaction to get to know the customers better, to make the right products, create more value, generate more sales, and build lasting relationships with customers, all for short-term and future revenue growth of the firm.

Typically, companies use CRM tools to manage sales as well as sales and marketing teams' productivity and growth. Customer Lead and Opportunity Management are two common processes in a CRM tool. CRM tools store a significant amount of information about customers. This information is kept private and the owner of the information expects to benefit from maintaining it. There is an abundance of CRM tools to support these typical companies which are single-sided: they support a single company interacting with its many customers. Its customers do not necessarily interact with themselves and the tool, designed for the single company selling to its customers, keeps information about interactions with customers private for the company.

In contrast, keystone business ecosystems are flat and open organizations. Members organize their activities and freely interact, collaborate, and share in an open environment. There is no top-down hierarchical control. It has a supportive environment and platform maintained by a keystone which may not be very noticeable because the keystone does not have a dominant role but a supportive one. Without the keystone the ecosystem cannot survive. This keystone ensures there are resources available on the platform for all members and the keystone ecosystem to flourish and prosper. The 
keystone is a catalyst for the ecosystem; the keystone is a shaper of the ecosystem in providing the ecosystem members what they need to survive and grow and to attract the right kinds of members. Relationships between all members and all different groups are important for the individuals and the entire ecosystem because of dependencies they have on one another.

A CRM that supports keystone ecosystems is not known to exist at this time. The known CRM systems support 'model A' single-sided companies, not model $\mathrm{C}$ companies operating on multi-sided platforms in a keystone ecosystem as defined by Bailetti (2010). CRMs that support model A companies are missing the keystone component required to support model $\mathrm{C}$ companies. Building on the components of an open source CRM for a single-sided model A company and adapting it for a multi-sided keystone ecosystem adds to management practice and academic literature on keystone ecosystems. It adds to the current design and practice of CRM technology and processes.

\subsection{Objective}

The objective of this thesis is to use existing open source software to construct a multisided platform that supports a keystone company that generates revenue through enabling deal-making.

The platform solves the following problems:

1. How to manage relationships between sides and members in a multi-sided keystone ecosystem with deal-making capability.

2. How to manage the health of the keystone ecosystem for productivity and growth.

\subsection{Deliverable}


This thesis delivers a software package of modules built on open source software which can be used to build a keystone ecosystem with capabilities for members to make money through deals. The research component of this thesis is to develop a model that allows individuals and organizations to assemble open source software to deliver a desired capability.

\subsection{Value of Deliverables}

Business organizations and management will benefit because this research offers:

1. A practical model for a deal making process in a keystone ecosystem with a multi-sided platform organization for its groups and members.

2. A way to make more money via subscriptions and transaction fees.

The following gaps in academic literature on keystone ecosystems and CRM systems are addressed:

- A keystone ecosystem that makes money

- A CRM system for deals in a multi-sided keystone ecosystem Model C business model as opposed to single-sided Model A company's sales (Bailetti 2010)

- The adaptation of an open source CRM system for a single-sided model A company to support a multi-sided platform with groups of companies in a model C business model for a keystone ecosystem with deal-making capability for its members.

Opportunities for future research include:

- ideas and a platform for customization and evolution in other areas of keystone ecosystem relationship management and operation based on feedback, use, and case studies 
- new keystone ecosystem platform tools and capabilities to build and manage these organizations with new ways of generating revenue

- application of more principles and rules from theory applicable to the traditional model A business model firms to model C keystone ecosystems

Limitations: This thesis does not include:

- tools for report generation

- testing the results of this thesis on a real keystone ecosystem and enabling it for deal making

- implementation of security mechanisms to limit access to data using the facilities of the open source

- infrastructure to track growth of resources and capabilities in members

- software to track and report on deal group formation, development, and productivity

- a nice customize user interface design

\subsection{Relevance}

The results of this thesis are relevant to two groups: (1) Keystones with roles as catalysts and shapers of an ecosystem: for establishing a keystone ecosystem, operating it, and managing it for strategic purposes; (2) Keystone ecosystem members, companies interested in joining a keystone ecosystem and taking advantage of the opportunities it offers to grow their company in that type of environment.

There is evidence in academic literature (Iansiti \& Levien 2004a, 2004b; Weiss, 2010; Bailetti, 2010) of the need to manage and monitor the health of a keystone ecosystem 
systematically. There is a need for them to be able to grow the ecosystem and member prosperity with measurable outcomes through deal making opportunities, being able to close deals faster than they could without the tools of the platform. Included in this group are entrepreneurship programs, start-up accelerators, incubators - all who need to apply principles and rules driven by theory and practice following a defined process with monitoring and data capture for improvement and the need to respond quickly. There is strong interest in entrepreneurship and the formation of start-up accelerators or incubators from academia, government, students, venture capitalists, and entrepreneurs. Economic development and company growth drives these interests. There is evidence that members will choose platforms that are operated and regulated properly with clear benefits for the members.

This thesis first develops a model for a software application that enables keystone ecosystem members to self-organize in deal development with capability to monitor progress and outcomes and make improvements for faster deal closure. It then develops the software.

CRMs are widely used by single companies for systematic sales and marketing management. There is a lack of a similar tool for multi-sided platform keystone ecosystems enabled with deal-making processes. In general we know such an application will be beneficial because of the requirements to...

1. drive systematic processes and information management

2. improve relations especially from value co-creation

3. close deals methodically and efficiently

4. bring revenue to companies sooner 
5. ensure the health of the ecosystem

6. manage relationships, groups and roles in the ecosystem

\subsection{Organization}

This thesis is organized into six chapters. Chapter 1 provides the introduction. Chapter 2 provides a literature review on all relevant streams upon which the thesis is based.

Chapter 3 is a description of the research method employed to produce the results.

Chapter 4 describes the results. Chapter 5 provides a discussion of the results. Chapter 6 provides the conclusions, identifies limitations of the thesis, and suggests future research. 


\section{Chapter 2. Literature Review}

Much of the literature review that follows is from strategic literature streams: the Resource Based Theory of the firm, dynamic capabilities, and strategy management, stakeholder theory. These streams are all related to one another and they are used to determine principles and rules for managing a keystone ecosystem enabled for deal making. I start with Customer Relationship Management (CRM) because that is where I started with the use of an open source CRM. It is mostly in the marketing literature stream but it also concerns strategy management, value co-creation, and performance which are concerns for managing the health and performance of a keystone ecosystem. Following CRM literature review, Multi-Sided Platform (MSP) literature is reviewed and that is because this thesis is largely about building a MSP. Keystone ecosystem literature is reviewed following MSP literature review since a Keystone ecosystem platform is a MSP and this is central to this thesis.

\subsection{Customer Relationship Management}

Payne \& Frow (2005) attempt to help solve the problem of CRM use leading to inconsistent results by providing a general framework of cross-functional processes for strategic use of CRM within an organization. There was a problem in having many views of what CRM is and how to implement it. A predominant practical view from industry was CRM is an IT solution for Sales Force Automation (SFA). Academics viewed CRM as being part of relationship marketing. Some saw CRM as being a call center. Thus, solutions were fragmented and results were inconsistent - some saw cost-benefits, many 
firms did not. Payne and Frow (2005) addressed the problem well with a reference framework which is very general but provides a standard reference to follow. It shows all that can be done with CRM from the highest-level view of CRM in a firm. I take it for this research on using a CRM technology tool to support keystone ecosystem enabled for deals because it shows what CRM is and by implication what it can mean for a keystone ecosystem. It also highlights the importance of the value co-creation which is highly important in this research.

Payne and Frow's (2005) research is based on interviews with executives who had used CRM and interviews with CRM vendors both who were mostly from large enterprise firms. The authors conjectured these types of firms would have the most challenging CRM and the best overall view of all possible types of CRM processes in use. A significant part of their criteria for a generic CRM framework was to have processes oriented towards strategy, processes which were cross-functional. A simplified model of the strategy framework for CRM is as follows: 


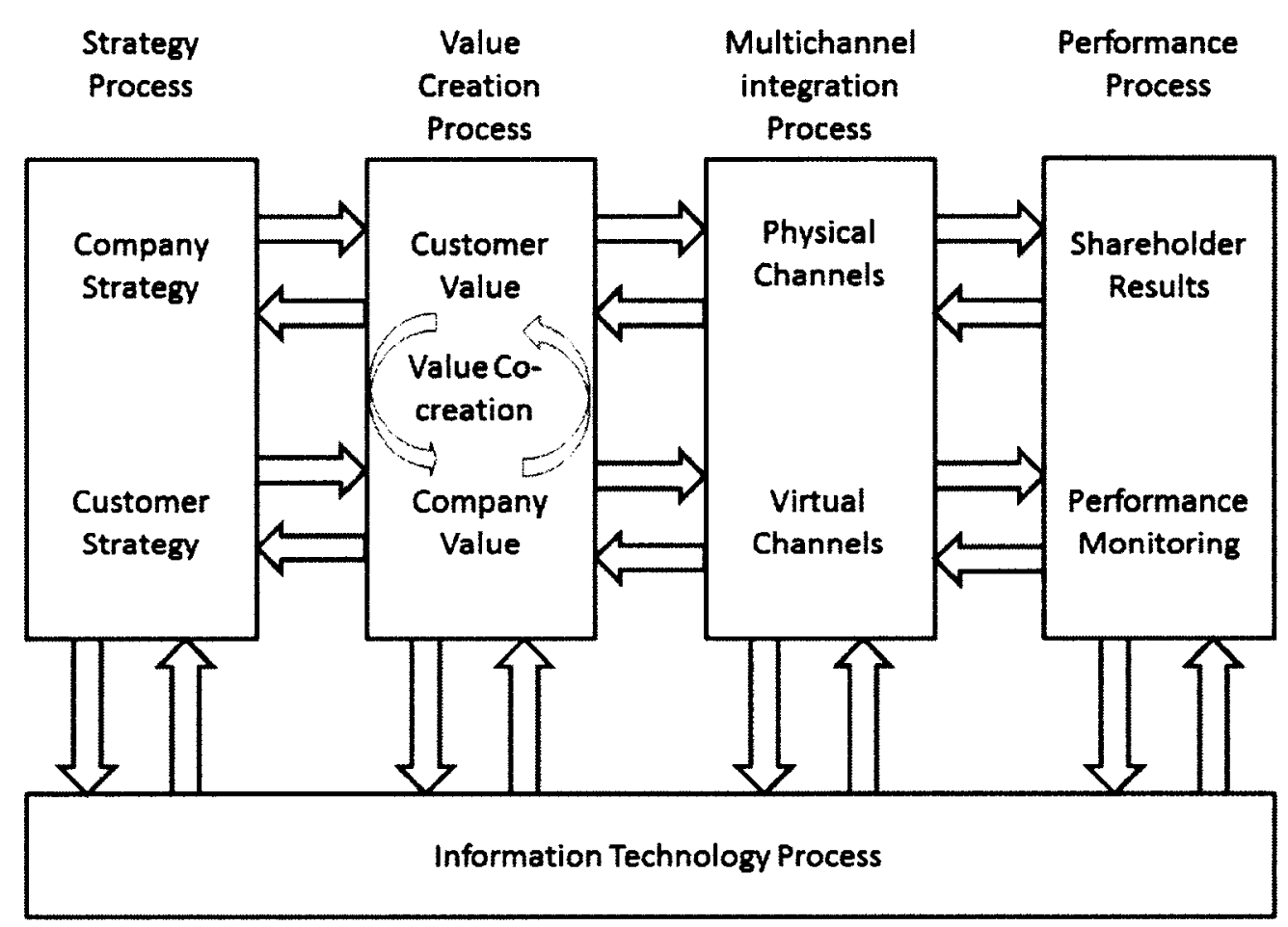

Figure 1 - CRM Strategic Framework (Payne and Frow 2005).

Since the framework represents a superset of all possible CRM processes, one would not expect to see all processes implemented in a single company in order to be successful. The information technology process supports all processes. All the information about the interactions with a customer must represent an integrated view.

The co-creation of value between customer and the supplier in the value creation process is very significant. The supplier company's value proposition is given to the customer and the supplier and customer interact to create value for the customer. It is a service logic view of value creation. Grönroos (2012) elaborates further on value creation as the only opportunity the supplier has to create value with the customer. It is the customer 
who determines the value by value in-use, the value to the customer determined by how the customer will use the products or services provided by the supplier. With performance assessment centered on benefit to shareholders, a firm can determine the benefit of CRM. Shareholders include employees, the supplier company, and the customers. All must benefit. It is essential to have performance monitoring with feedback loops providing timely data from the cross-functional processes for status assessment and action.

The value creation process was researched further by Payne Storbacka and Frow (2008). It is a process of co-creation of value with the customer. The authors describe how to manage value creation using service dominant logic. It places the customer at the center of the value-creation process with developers/suppliers. Knowledge is important for strategic purposes. A lot of customer knowledge in a large firm is tacit knowledge and Payne et al (2008: 90) say this suggests the importance of organizations to design knowledge management activities around value co-creation processes. Payne et al (2008) say it's important to focus IT investments around customer processes and experiences rather than around products. Encounter processes are where customer and supplier interact. It is recommended to increase dialogue and focus on the value of the relationship rather than just the monetary transaction. There are communication, usage, and service encounters. One manages value creation processes by setting goals for customer and supplier and evaluating achievement of these goals. Peelen et al (2005: 453) say CRM Technology is used to support '... mutually profitable long term relationships with customers and other stakeholders. It requires vision, strategy and organizational change.' This is consistent with Payne \& Frow (2005) but they note 
the problem that it has not always been easy or profitable to implement the crossfunctional processes in an organization and IT Technology required for CRM success. The research is an empirical study into CRM successes, accomplishments and difficulties. It provides empirical knowledge of the relationships between CRM strategy, customer information, customer interactions and processes to help understand reasons for success and failure in CRM. The results show success in using CRM will be achieved if companies focus on (1) vision and strategy which are highly correlated (2) CRM information and processes which are supported by technology. Vision and strategy have a positive impact on the customer experience (client oriented interactions) and these have an impact on organizational collaborations. There is no direct relationship between vision and strategy and customer experience and organizational collaborations. Strategy and vision are important in guiding CRM Processes and Information. Maklan and Knox (2009) address the common problem of lack of returns of investment in CRM from the perspective of dynamic capabilities. Though their findings are only based on two case studies, they suggest organizations must identify and develop their dynamic capabilities to support their CRM. With this approach, organizations would concentrate less on using static resources, such as branding, for competitive advantage and instead they would determine how these resources and capabilities can be created, developed then used for competitive advantage. Instead of deploying CRM technology with built-in process support, the authors maintain it is better to train marketers in relationship marketing capability and develop better marketing programs to change customers' attitudes and behaviour. 
To assist, Maklan and Knox (2009) proposed a framework for dynamic capabilities in marketing (Maklan \& Knox 2009: 1395). One dimension is the type of relationship between customer and supplier organization. The marketing relationships are: (1) transactional (2) one-to-one (3) network. It is not possible to skip a level. An organization progresses through the sequence in its capability development. Therefore, an organization's current level of capability determines its customer interaction strategy options.

The other dimension of the framework is dynamic capabilities for marketing which are (1) demand management (2) creating marketing knowledge (3) building brands (4) CRM. The highest level of marketing capability is through the use of CRM with networked marketing relationships. At that level, the dynamic capabilities are manifested by network capabilities, self-managed consumers leveraging colleagues' know-how.

\subsubsection{Lessons Learned: CRM}

It's most important to use CRM for strategic purposes and the strategy framework of Payne and Frow (2005) identifies important cross-functional processes to be used. Value co-creation with the customer is most important.

It's important to use the data from CRM processes for strategy. Having CRM and not using the results will not be profitable or useful. One must have vision and strategy to make CRM profitable.

Dynamic capabilities are important to make CRM useful and profitable. The framework of Maklan and Knox (2009) for applying CRM and dynamic capabilities with marketing is useful for knowing and managing the type and level of relationships with customers. Using Networking and CRM, the highest level, besides relationships with customers, 
relationships with suppliers may be used to take responsive actions to situations and issues as they arise.

\subsection{Multi-sided Platforms}

To understand how CRM for a single-sided company can be evolved to support relationship management in a Multi-Sided Platform (MSP) keystone ecosystem it is necessary to understand what is meant by a platform and then what is a multi-sided (sided) platform. This section is also concerned with regulation and governance of a MSP. As stated in the introduction, this is relevant to this research because it is about MSP keystone ecosystems and there is a platform aspect to it which the keystone maintains and operates for benefit of the entire ecosystem.

\subsubsection{Multi-Sided Platform Definition}

Boudreau and Hagiu (2009: 2, footnote 2) provide a working definition of platform and multi-sided platform:

"Platforms are products, services or technologies that serve as foundations upon which other parties can build complementary products, services or technologies... A 'multisided' platform or MSP (e.g. Sony's PlayStation, Visa credit cards, Microsoft's Windows, eBay) is both a platform and a market intermediary (Hagiu 2007). Thus, distinct groups of consumers and 'complementors' interact through MSPs." The Boudreau and Hagiu (2009) definition of a platform is commonly accepted but their definition of a multi-sided platform lacks refinements. Hagiu and Wright (2011) makes a proposal to distinguish amongst what constitutes (1) a merchant platform (2) a pure multi-sided platform (which includes two-sided platforms) and a (3) re-seller. Their definition of a multi-sided platform is: “.... an organization that creates value primarily by 
enabling direct interactions between two (or more) distinct types of affiliated customers." (Haigu and Wright, 2011: 7). The words in italics are ways in which a pure MSP can be different from other existing definitions.

The organization making up a MSP need not be just a single company. It can also be a group of firms, not-for-profit organizations, cities, or Multiple Listing Services. The primary value of a MSP is to enable direct interactions between members on different sides through their common affiliation to the platform. Indirect interactions are possible but not a main distinguishing attribute of a MSP. For example, it may be possible for people going to a jazz club to make connections socially but that is not the primary value of the platform to them and it is not due to their primary affiliation with the platform. They go to hear the music they like. Some previous definitions of MSP emphasize the importance of indirect network effects as a defining characteristic (:6). This research goes with the choice made by Haigu and Wright (2011) with direct network effects being of prime importance for direct interactions with members of common affiliation to the MSP.

Direct interactions between MSP members on side A to members on side B may also involve contracts. In such cases, a pure MSP allows members in the interaction to have control rights to the activities. They are not controlled by the platform. For example, the contractual agreement between a buyer and a seller on eBay is not controlled by eBay. PayPal is provided as a service to the parties interacting directly and making an agreement but eBay has no control over the agreement between buyer and seller. eBay is a MSP in these respects. 
The enabling attribute of an MSP is important. A pure MSP provides capabilities to enable direct interactions between members on different sides, of common affiliation, to create value together on or through the MSP. The interactions enabled are relevant to the affiliation of the members to the MSP and the MSP enables them to happen through what it offers. For example, because BestBuy sells warranties on products people buy at BestBuy this does not make BestBuy a MSP. BestBuy does not enable a direct interaction between buy and product manufacturer by warranty sales made by BestBuy. An exchange between buy and seller is often preceded by a communication also offered by the MSP. Some MSPs also allow for consumption. For example the Apple iPad allows for communication, exchange, and consumption of an app between a consumer (customer user of the iPad) and the supplier of the app. Apple's App Store lets users browse and search applications in the store, purchase them, and run them on the iPad. (Hagiu and Wright, 2011:13). eBay only enables communication and exchange. Prior to providing applications on cloud services, the Windows operating system only enabled consumption of applications on personal computers.

Affiliation with the platform: According to Hagiu and Wright (2011: 13), a member of a platform is "affiliated" with it when he/she makes a conscious decision to participate which is peculiar to the platform and which is necessary in order to interact directly with other members. That is, there must be a registration or joining process to become a member and to be enabled to participate on the MSP with other members. There is usually some forms of investment such as (1) opportunity costs due to effort and time to learn and use the interfaces to the platform (2) membership price or transaction costs. 
In summary, the following figure distinguishes between MSP, Re-Seller, and Input Supplier. It is adapted from Figure 1 in Haigu and Wright (2011) which shows the simplest case of an MSP: a two sided platform. The existence of two or more sides is indicated in the figure below.

According to the explanation given above on what is an MSP, the diagram for the MSP in the figure below shows that the MSP enables direct interactions between affiliated members of the platform. A re-seller does not provide direct interactions between members on different sides. It purchases goods or services from suppliers and sells them, potentially under a different brand name, to its customers. An input supplier firm merely supplies products or services to customers of different types/groups who interact directly themselves with their customers. The input supplier has no connections to interact with customers of the firms it sells to directly. 

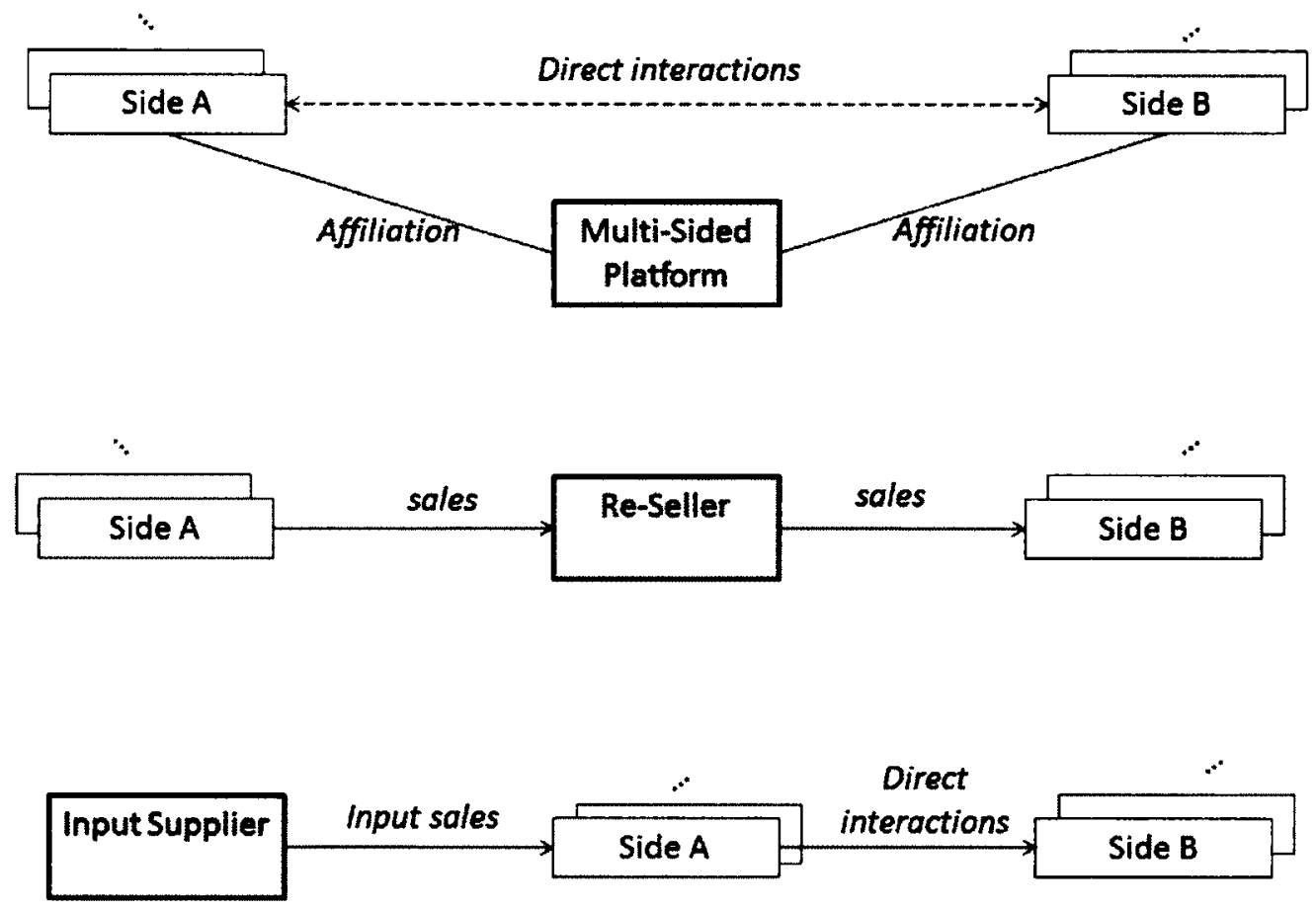

Figure 2 - Differences between MSPs, Re-Sellers, and Input Suppliers

\subsubsection{Multi-Sided Platform Regulation}

Gawer and Henderson (2007) is a study of Intel's entry and non-entry experiences with complementary markets in the personal computer industry. It provides the following definition of a product as a platform (: 4$)$ :

'...we define a "product" as a platform when it is one component or subsystem of an evolving technological system, when it is strongly functionally interdependent with most of the other components of this system, and when end-user demand is for the overall system, so that there is no demand for components when they are isolated from the overall system.' 
All except shared input markets, to an extent, assume complementary markets on different sides are predefined and well known and the platform intermediary's role is static. Most papers on two-sided market platforms seem to be mostly concerned with price controls: fixed fees for complementors or variable fees or royalties from patent usage. There are other concerns with keystone ecosystem multi-sided platforms and especially those with a unitarian approach in their stakeholder strategy-seeking the benefit of all sides. There is more on this topic later.

Gawer and Henderson's (2007) research on the Intel complementary market entry strategy is a good example of vertical integration and horizontal integration. The research was on bundling and complementary market entrance. Other two and multi-sided market studies typically are concerned with network effects or platform dynamics (Rochet \& Tirole, 2003; Hagiu, 2004).

The reason for entering complementary markets is to enter new markets to gain profit for the entrant platform owners and gain for the consumers. As in the case of Intel, sometimes we see a platform not trying to compete with a complementor in an adjacent market and give assurances that they do not intend to do so. Intel wisely made this choice many times to great success. Complementors were also encouraged to make more innovative development to attract users and thus provide more value to the platform as well as themselves.

Intel's strategy was to use what Gawer and Henderson (2007) refer to as 'connector markets' such as chipsets and motherboards in order to allow users to connect to applications in a stack of complementary markets. The Intel microprocessor platform is at the bottom of the stack, connectors are in the middle of the stack, and user applications 
are at the top of the stack. Intel drove the development of interfaces (APIs) to have platform adoption and then get market entry and control of the interfaces. When entering a new vertical or horizontal market, Intel often strategically gave promises they would not take too much profit or they promised to not compete with a complementor. There had to be a trust relationship as well since Intel was usually more powerful than the complementors. Frequently, in these situations, Intel subsidized complementor development because the innovation led to increased user demand for applications running on the platform. Thus, connectors were strategic in connecting Intel's platform to other vertical and horizontal markets. Intel controlled them and application users were unaware of them. The connectors drove demand for applications which in turn drove demand for the platform.

Boudreau and Hagiu (2009) describes four interesting, well known and successful cases of multi-sided platforms which evolved towards clear and sometimes strict rules for platform participation which are not solely based on price controls. They are the social networking site Facebook, TopCoder, the Japanese real estate firm Roppongi Hills' "mini-city", and Harvard Business School. They all faced failures which were not centered on price for participation but they were centered on factors such as: externalities, information asymmetries, complexity, non-pecuniary motivations, and uncertainty. Evidence from these four case studies lend support to platform regulation by such means as regulation of platform access and interaction, contractual, technological, informational, and price controls.

In each case, the platform owners had to set boundaries and rules of conduct for groups and members. Owners had to provide the technical architecture to frame interactions, 
encourage complementors to make investments, manage and maintain the overall "health" of the ecosystem. In the mini-city of Roppongi Hills in Japan, it was interesting to note how the platform owners had to sometimes ask highly visible companies to leave simply because the way they operated and their brand did not fit in with the environment and experience offering of Roppongi Hills. Platform benefit was of paramount importance. The owners controlled who was in and who was out so the platform could survive and so individuals could do well and do well together.

Boudreau and Hagiu (2009: 164) give a comprehensive list of roles of platform owners from various research papers:

- Assuring 'coherent' technical development and coordination among contributors to an MSP ecosystem.

- Design the technical architecture that frames [enables] interactions.

- Encourage complementors to make investments [in resources or capabilities which will be of benefit to the platform].

- Generally managing and maintaining the health of the ecosystem.

The rationale for platform regulation may be summed up as: (1) the various types of externalities around the platform and the need to control coordination (2) multi-sided platforms (MSP) focal position enables them to be private regulators (3) owners of MSPs have instruments, incentives, and resources to be the regulators of their platform. The case studies in Boudreau (2009) apply to keystone ecosystems.

In regulating an ecosystem, it can be viewed as a collection of firms or small companies engaged in co-production with interdependent choices and actions. They make decisions 
such as entry, investing, technological development or use, prices, advertising etc. but done in cooperation with other members. The platform owner does not take direct actions himself regulating the platform. Decision making can be distributed amongst a group. Interdependence amongst group members arises from the presence of externalities. Therefore when decision making is public it results in stronger commitments to agreements than when they were made in private. It therefore enables more public commitment based agreements versus process based agreements (Sull \& Spinosa, 2005), which are common in large firms with well-defined processes with decision points after their execution.

Without regulation of platform operations and processes, we would see members trying to maximize individual profits which limits surplus for the platform and benefit to the rest of the community. Left by themselves to operate, member firms find it difficult to engage in cooperation, coordination, and collusion activities (Evans, 2005).

Some may be tempted towards public regulation of a platform. Past evidence has shown that for ecosystems it does not work well (Boudreau and Hagiu, 2009: 169). Public regulators use blunt instruments, it is not practical for an ecosystem, and they are too costly. The platform owner has the information advantage to govern and he/she has access to various instruments. Unlike public regulators, a platform owner has an incentive to perform good regulation because he/she profits from it. The owner's profit is derived from the overall value of the ecosystem to members. It could be viewed as a tax on each sale or as a percentage of value from each relationship. A danger may be the owner's temptation to take too much of the profit for him/herself. A keystone ecosystem 
does not operate this way and there are ways to set up the governance structure to prevent this from happening in an open ecosystem.

The four case studies in Boudreau and Hagiu (2009), TopCoder, Harvard Business

School, Facebook, Roppongi Hills, showed considerable amount of rules in regulation of interactions between complementors and users. This required by-laws for conduct, participation game rules, and controls and inducements e.g. management of privacy to minimize negative network effects in the case of Facebook in particular. Initially at least, Facebook restricted membership to particular social groups to grow the member base. Later, it gradually opened it to all for benefit of the platform. It appeared opening the platform to everyone netted a lot of profit for Facebook while being only a slight inconvenience to members.

TopCoder had a problem finding out which competitors had the right qualifications. The solution was to set up a system of prizes, peer recognition, and visibility to attract people to TopCoder, reward participants, and monitor abilities and successes.

Harvard Business School (HBS) indicated they had to carefully monitor interactions between students and recruiters in order to preserve relations between academics and students for research. Harvard wanted the students to complete their degrees, and preserve the HBS reputation, then find a job.

\subsubsection{Lessons Learned: Multi-Sided Platforms and their Regulation}

1. The platform owner must collaborate and cooperate with complementors, give incentives to them, build trust, and attract the right ones to the platform in order for it to flourish. 
2. There is a strategic benefit in developing and controlling interfaces (APIs) to the platform to build stacks for vertical market entry and horizontal movement into complementary markets.

3. The platform owner must be aware of the benefits of network effects and the ability of complementors to draw business indirectly to the platform-the platform owner has a prime responsibility to take care of the relationships, help them grow, and to not impede their innovations.

4. Regulation of a MSP is necessary and at the core of business models in all cases.

5. Regulation involves use of a wide range of instruments and combinations of legal, technical, informational, and price setting.

6. Two step approach for the owner:

a. Maximize value created for the entire MSP.

b. Maximize value extracted.

7. Don't have too many instruments for operation and strategic management of the platform. After a certain point, there is little more to gain.

8. There must not be any profit-taking practices by platform owners?

9. Managers are not to focus only on product, price, and technology but control interactions beyond the firm boundaries.

10. Active early orchestration of regulation can put strong network effects and strong complementary interactions into motion very quickly.

11. Platform owners have to set up systems of reward and recognition for members as inducements to perform, to monitor it, to reward them and give them recognition. 
It is also an indication of platform performance and improves interactions and relationships.

\subsection{Sided Markets, Network Effects and Externalities}

\subsubsection{Sided Markets}

Rochet and Tirole (2003) is based on the premise that when network externalities are present, most markets are two or multi-sided markets. Their research combines research streams on network externalities and research streams on multi-product pricing. Previous research on network externalities ignored multi-sidedness and price allocation strategies. Multi-product pricing literature ignored the affiliation externalities, which are at the core of network externalities while they covered interdependencies of pricing decisions. Rochet and Tirole (2003) is most closely related to two-sided market literature on the chicken-and egg problem but that literature assumed the platform has a monopoly position in the market.

Their research shows how the price allocation between the two sides of the market is affected by:

1. Platform governance (for-profit, not-for-profit)

2. End-user cost of multi-homing

3. Platform differentiation

4. Platform ability to use volume-based pricing

5. The presence of same-side externalities

6. Platform compatibility.

It also investigates how privately optimal pricing structures compare with socially optimal ones. 
Rochet and Tirole (2003) gives an economic model to describe price structures for different governance structures in two-sided markets: (1) private monopoly (2) Ramsey Planner, which is a neo-classical economic growth model, and (3) competition between for-profit and non-profit platforms.

There are results and implications for public policy and business.

The public policy implications are:

1. The Ramsey pricing structure is not a fair-cost allocation achieving socially optimal results as usually intended. It is used to get both sides of the market on board, as with a private business cost structure.

2. To attract users on one side, a Ramsey price structure takes into account the average net surplus created on the other side with the addition of one new user on the opposite side. Private business models for price structure do not show any price structure bias. In the linear demands all private price structures are Ramsey price structures.

The business side results are:

1. Getting both sides on board the platform is important for both monopoly and competitive platforms - the price structure must be set to achieve the goal of getting participants to join.

2. If buyers on the buyer side multi-home, then this facilitates steering on the seller side. The price structure becomes more favourable to sellers in this situation.

3. If marquee buyers are present on the buyer side, then this raises the seller price. If there is also no price discrimination on the buyer side, this lowers the buyer price. 
4. If there are captive buyers on the platform, then the price structure is altered in favour of the sellers.

Rochet and Tirole (2003) give seven small case studies on which they suggest their results can be tested: (1) credit and debit card platforms (2) the internet (3) portals and media (4) Video Games (4) Streaming media (5) Operating Systems and (6) Text Processing.

In sided markets with network externalities, there can be cross-subsidies between sides or categories of users. The platform owner can subsidize one side to attract the other -attract more buyers to make more sales at reduced prices. Not only is price the determining factor for volume of transactions and profit for the platform. The price structure is also important. Exceptions can occur and cross-subsidization between buyer and seller will have no effect when both sides of the market/platform negotiate the transactions outside the platform. An example of this could be when an internet provider makes a special deal with a company to provide intranet services. There would be no increased attraction to the platform for such deals. Another case of cancelling the effects of cross-subsidization is called pass-through (of extra costs) and neutrality. Value-added taxes are an example of neutrality. It doesn't matter whether the buyer or seller side pays the tax, in the end after all prices adjust, all costs to the sellers are passed through to the consumers. In such cases of neutrality, these are really one-sided markets, not two or multi-sided markets.

In all examples given in Rochet and Tirole (2003) the authors give their perception that it is hard to imagine these two or multi-sided markets/platforms operating as one-sided market/platform. The owners pay a lot of attention to price allocation business models 
with goals of attracting one side only to entice the other for benefit of the platform. End users are sensitive to costs allocated between them (their sides) indicating some price distribution is taking place.

Pass-through and neutrality of the platform is not possible mainly for three reasons:

1. Transaction costs: which are often either too small or too many and varied making it not cost effective to build monitoring and reporting tools to pass them through to the consumer

2. Volume-insensitive transaction costs: such as when developers pay to use development tools specifically for applications for a platform for use by consumers of the applications; when developers have to learn the APIs to use a platform these are volume insensitive fixed costs

3. Platform-determined constraints on pass-through: such as when one side is subsidized and these savings are passed on to all the consumers on the other side even those not using the platform. For example, credit card companies passing discounts on to merchants who pass discounts to all their customers, not only card carriers.

\subsubsection{Network Effects, Network Externalities}

In the case of Katz and Shapiro (1985) and Liebowitz and Margolis (1994) and research on network effects in general, the context is buying from a network. Liebowitz and Margolis (1994: 135) state the meaning of network effect as follows:

'The circumstance in which the net value of an action (consuming a good, subscribing to telephone service) is affected by the number of agents taking equivalent actions will be called a network effect. ‘ 
Katz and Shapiro (1985) describe direct and indirect network externalities. The type of externality depends on whether there is direct or indirect contact with buyers of a product or service. Indirect effects become very important to consumers. The presence of complementary goods is an indirect network effect of the purchase of goods and it is very important in the consumer desire to purchase a good. The general principle is that complementary goods and services increase in number and decrease in cost as there are more users or purchasers of a product or service. This makes the product or service more attractive to buy.

There are two ways to internalize network effects: (1) through ownership or (2) through transactions.

It is common to resolve problems with externalities using means such as setting property rights, government regulation, and private negotiation between parties. If competing firms were to internalize externalities amongst themselves, this would result in a cartel or monopoly, which is to be avoided of course because it is deemed market inefficient in an economic sense. Liebowitz and Margolis (1994) point out that internalizing through ownership does not always solve the problem of network externalities as often expected-under the assumption that the owner can make adjustments to prevent market failure. For example, a network owner cannot indefinitely offer below margin cost products or services to ensure adequate participation in the network. The authors make the point about solving the commitment problem, having participants make a commitment to join the network, by charging a price to join each period. It reduces their risk. 
For an example of internalizing through transactions, consider the example of internalizing by how participants interact such as the case with a group of open source software developers all interacting with the same language. Though others outside their network may be able to speak the same language, it is important that the members of the interacting group of developers all use the same language and thus internalize network effects. "If transactions are relatively easy to make, then the existence of a network externality is unlikely.“(Liebowitz \& Margolis, 1994: 44).

There is not much support for the claims often made about the presence of network externalities. Two famous examples cited by the authors are the typewriter keyboard format, QWERTY versus Dvorak, and VHS versus Beta videotape formats. Data indicates the markets did not fail: QWERTY is better than Dvorak, and VHS is better than Beta as determined by the market.

There is a big challenge to economists using network externalities in their arguments. '...theoretical literature establishes only that within models that incorporate particular abstractions, market failure of the type that causes the wrong network to be chosen is possible.' (Liebowitz \& Margolis, 1994: 148). Therefore we may not often have valid claims and network externalities may often be irrelevant.

There is scant evidence for network externalities though they are present in our economies. Most are merely pecuniary (monetary) effects. Most that appear like network externalities are really just a result of technological advances.

\subsubsection{Lessons Learned from Sided-Market Theory and Network Effects}

- Principles of two-sided market theory or platforms apply to multi-sided markets or platforms 
- A multi-sided keystone platform has to have chicken-and-egg problems solved to get all sides on board.

- Getting the right sides which are attractive to other sides is important. We need the right number of members on each side and a price structure must be set.

- The price structure is important and must be constantly managed for the benefit of the platform.

- Be aware of direct and indirect network effects. With a keystone there is the advantage of being able to internalize network effects through both ownership and transactions.

\subsection{Keystone Ecosystems}

Iansiti and Levien (2004) describe what a business ecosystem is with analogies to biological ecosystems throughout. Their stated purpose in doing so is to emphasize the utility of this approach in understanding what a business ecosystem is and to show the strategic benefits of thinking this way. Many examples of large companies are given as well showing how they operate using the ecosystem approach and how they affect ecosystem members by their actions, or how a single action by a member can affect the ecosystem. Of particular importance is a keystone ecosystem where the keystone has strategic roles to perform in monitoring and maintaining the health of the ecosystem. An important contribution from Iansiti and Levien (2004) is a framework for gauging the health or performance of an ecosystem.

Business ecosystems have unique attributes and behaviour such as: 
1. Loosely connected networks made up of groups of various types who are affected by the development and delivery of the firm's products or services or who are affected by them.

2. Interdependency between groups and members

3. Ecosystems create platforms of services, tools, or technologies to build capabilities in members and groups in the ecosystem develop their capabilities.

4. Collaboration and coordination effort.

Because of their interdependencies, members of an ecosystem share success and failure together. If one does poorly, others are affected. Hence it is important to keep them all healthy. If all members are healthy, the ecosystem is healthy. It is the keystone's role to monitor and maintain the health of the ecosystem. This is done by ensuring members and the keystone platform itself are (1) productive (2) the ecosystem is robust and (3) niches are created.

Robustness basically means how well the system can survive in the face of difficulties or negative events. It can be measured in terms of (1) how predictable its performance is (2) how well the ecosystem and members can withstand negative events and (3) how well relationships survive against negative external shocks.

A very healthy ecosystem will show development and evolution of niches of specialization and diversity. It is the ultimate test of health for an ecosystem: without niches being produced, an ecosystem cannot be healthy and will not survive. Having a keystone in an ecosystem is a significant advantage for the ecosystem. For a large ecosystem, a keystone ecosystem is a group of member companies occupying a key position where it can promote the health of the ecosystem by providing a 'stable and 
predictable set of common assets' (Iansiti \& Levien, 2004: 6). The keystone may provide a platform of tools or services to the members of the ecosystem to help them create value. An effective keystone strategy has two parts: (1) being the first to create value within the ecosystem (2) share the value with others in the ecosystem. But the keystone also keeps a share of the value created and thus prospers as well as the members. A strategy may be the keystone approach as described above, or it could also be the dominant approach, or the niche approach. A physical dominator is identified as one who tries to get control by vertical and horizontal integration. In so doing they can take over much of the ecosystem. The value dominating strategy is taken when the ecosystem member/organization tries to take over control of the ecosystem and take as much of the value generated by it for itself.

The strategy of the niche approach is cited by the authors as the most common approach. Complementary resources are leveraged by the niche player for him/herself. Niche strategists typically make most of the value creation and innovation in an ecosystem. They know how and where to get the resources they need to use with those they have. They can be seen being close to the keystone or a dominator. Niche players grow and advance their boundaries in the ecosystem. If they fail to advance to the edges of the ecosystem themselves, niches may be taken over by an expanding platform.

Business ecosystems are often described very narrowly though examples from biological ecosystems offer a breadth of possibilities for interpretation (Weiss, 2010). The examples and descriptions of most business ecosystems describe keystones as a noun, taking on the role of a catalyst or a shaper for the ecosystem. This is true and it is very 
clear and applicable to the term keystone used in this research; however it is also possible to have a keystone species, more than one member of a particular type which is the keystone for an ecosystem. There could be multiple keystones for an ecosystem. One may use network analysis techniques to examine the relationships between members of an ecosystem to discover the keystone or keystones in it.

It is also a misconception that the keystone dominates the ecosystem. Instead, the keystone is a catalyst or a shaper of it. Note this is consistent with Iansiti and Levien (2004), which said keystones do not dominate and control. They provide a supportive platform with resources for members to share and with which they can collaborate. The keystone, as a shaper, will provide complements to the platform to enable business to flourish. Note that this is the point of view taken in this thesis though as Weiss (2010) asserts, other possibilities do exist.

Finally, a third misconception that Weiss (2010) articulates is the keystones of ecosystems are not necessarily active leaders. They may be inconspicuous due to the lack of a top-down hierarchy of control of the ecosystem. This structure is consistent with the flat and open architecture described for systems of open innovation (Pisano and Verganti, 2008; Chesbrough, 2003; Chesbrough and Appleyard, 2007). The keystones role is more about ensuring the adequate supply of resources rather than being the dominant leader of the ecosystem.

Bailetti (2010) gives a revenue growth model that applies to a keystone ecosystem described by lansiti and Levien (2004). It steps away from the analogies to ecological ecosystem behaviour and delves into business models for making money in a multi-sided 
platform ecosystem which is a keystone. It compares and contrasts the familiar one-sided single company business model, called "model A", with the multi-sided keystone platform way of doing business, "model C". See Appendix A for a diagram of the two business models. In the single company model A approach, a company sells to its customers either directly or through intermediaries. It is on its own or dependent on the intermediaries to get through to customers for revenue. In the model $\mathrm{C}$ approach, there are groups or organizations on different sides of a multi-sided platform. All have affiliation to the platform which offers services, technology, and/or tools to members. The groups or sides are complementary to each other with network affects and dependent relationships for generating revenue together, going to market reaching customers. The model C approach has the keystone advantage described by Iansiti and Levien (2004) as well.

In this model, the keystone operator/owner is described more as single person though there does nothing to indicate it could not be an organization or group. For revenue generation, the keystone in a model $\mathrm{C}$ business environment has two key responsibilities:

1. increase the volume of transactions by members

2. increase the efficiency of creating new products and services Thus they are concerned with making money. To accomplish these goals, the keystone has activities and responsibilities (1) setting vision, leadership and governance (2) defining member classes, price structure for membership in each class and costs for transactions between members (3) maintaining ecosystem health (4) member recruitment (5) setting the intellectual property regime (6) providing knowledge sources for members 
(7) providing tools, technology, or services for members to self-organize, address their needs, and add value to the ecosystem.

Members are put into sides which are defined according to what value members obtain from the keystone platform.

\subsubsection{Lessons Learned: Keystone ecosystems}

- The business ecosystem approach to business is a good strategy to follow.

- There are many advantages to take the keystone approach.

- A Keystone approach with the Niche building strategy is best.

- Beware of dominant strategies and take care to prevent them with proper rules and governance structure.

- The niche approach is very similar to the resource based theory which emphasizes heterogeneity, specialization or co-specialization, and dynamic capabilities.

- The characteristic behaviours of large business ecosystems apply to small ecosystems but on a much smaller scale.

- Business ecosystems have a limited view of what ecosystems are or could be compared to the possibilities seen in biological ecosystems.

- A keystone ecosystem could have one keystone acting as a catalyst or shaper or there could be a group of them.

- Use the model $\mathrm{C}$ business model for a keystone business ecosystem to make a keystone that makes money.

- Besides responsibilities for growing and developing the platform, the keystone has specific roles related to ensuring the keystone members make money and stay healthy. 
- Small companies stand a better chance in a keystone using the model $\mathrm{C}$ way of doing business.

\subsection{Resource Based Theory}

The Resource Based View (Theory) of the firm is used in this research because it is believed by the author that it provides a practical way of building and managing a group of companies strategically. It is a possibility that a keystone ecosystem could be built from scratch rather than finding one that already exists. This theory provides a way to do it. The research question is concerned with how to enable a keystone ecosystem for making money and the solution put forth is through deal enablement. The Resource Based Theory (RBT) is a practical way to look at the capabilities and possibilities through what resources are available. When a member joins a keystone ecosystem, as they would for a traditional single-sided company, it is practical to ask what resources or capabilities they bring to the platform. How can the complement what is already there. For the overall keystone ecosystem, the keystone needs to know what resources do they have to operate with. How can they be used to generate revenue in deals and what strategic options can be pursued. These kinds of questions exist for single-sided companies and it is believed they are valid questions for managing keystone ecosystems.

A firm's resources are assets, capabilities, processes, firm attributes, information and knowledge, etc. which are controlled by the firm and which enable it to implement strategy, build efficiency and effectiveness (Barney 1991: 101). They may be classified as physical, human, and organizational capital. Chatterjee and Wernerfelt (1991: 35) 
categorize resources for the purposes of their study on resources and diversity as physical, intangible, or financial.

Taking a resource based view of a firm gives one a different picture of the firm potential for building new products, services or capabilities and entering new markets than if one were to take a product based view. Wernerfelt (1984) introduced the use of a resourceproduct matrix to evaluate a firm's resource position and to determine strategies for product-market activities. It enables one to answer practical questions about diversification and market entry such as: (1) what resources can/must be used (2) what resources can/must be developed (3) what markets can be entered and in what order should they be entered (4) what acquisitions must be made to gain the resources needed to execute the strategy for entering a market. A balance must be struck between use and development of existing resources and the acquisition of new bundles of resources. Peteraf (1993) developed a general economic model to relate firm resources and performance. It states four conditions necessary for competitive advantage (Peteraf 1993: 185): (1) Resource Heterogeneity (2) Ex post limits to competition (3) Imperfect mobility (4) Ex ante limits to competition.

To have a sustained competitive advantage, resources must be distributed heterogeneously between firms. Having superior resources in limited supply and/or being more efficient using them will usually enable a firm to earn more rents than competitors. (Economic rent is earnings in excess of breakeven which are not considered to be profits because they do not lead to new competition (Peteraf 1993: 180 footnote 4).) If profits are high, it will attract competitors into the market with possibly inferior resources and they may still be able to compete and make a profit. Firms with superior 
resources can keep their competitive advantage by ensuring these resources stay within the firm, they cannot easily be expanded on or imitated by competitors. The core competencies of a firm, particularly if they are knowledge based and learned collectively, can be enhanced as they are applied. They may also form the basis of strategic direction for growth and become part of the knowledge base of the firm.

If a firm achieves a superior position in a market the condition of resource heterogeneity must be maintained in order to limit competition and sustain its competitive advantage. This is the factor called 'ex poste limits to competition', the second economic attribute for sustained competitive advantage in the resource based view. To ensure a superior position due to having superior/scarce resources, a firm has to ensure they are imperfectly imitable and imperfectly substitutable. Common mechanisms include property rights on scarce resources, information asymmetries, and various types of impediments to imitation. If it is hard to determine the cause for a firm's superior achievements, what they are or how to go about imitating them, then the condition of resource heterogeneity will be easily maintained. Resource based assets which develop within a firm are particularly hard to imitate mainly because they are tacit and socially complex: they tend to be developed within teams with a history of learning and asset accumulation. Resources developed this way also are imperfectly mobile, stay within the firm, and this is the third economic factor from Peteraf (1993) for sustained competitive advantage. Imperfectly mobile resources of a firm are not easily traded and this may be a result of property rights or being peculiar to the firm where they were learned and developed. They may be tradable but imperfectly mobile due to having more value within the firm because of their developmental history. If developed with other resources within the 
firm, both may be cospecialized assets and of more value being together than being separated from each other. There may also be some switching costs if resources are traded out of the firm. It may be of less value to another potential owner than the original one. Regarding rents and the immobility factor of resources for sustaining competitive advantage, imperfect mobility of resources is a necessary factor for sustainable competitive advantage because they are immobile and remain available for use by the firm and because the firm will share rents with the resource owner. Rents are ' ...jointly produced and are as much due to the firm as to the factor.' (Peteraf 1993: 184). The last factor 'Ex ante limits to competition' means a firm about to develop a superior resource position must have limited competition for the resource if it is to be successful using it to implement a strategy for economic returns. If competition for the resource is high, this could drive up the costs for achieving it and this would lead to it being not a superior resource position. Ex ante limits to competition takes into account the proposition from Barney (1986) which states the economic performance of a firm depends on their returns from their strategies and on the cost of implementing them.

Sirmon, Hitt, Ireland and Gilbert (2011) assert that the role of managers has been ignored in RBT. The authors summarize results from research and practice from the previous two decades regarding organization management, business strategy, and competitive dynamics with many practical examples of processes and strategies. They present arguments for a new research stream called 'resource orchestration' which is an integration of existing frameworks of resource management and asset allocation both of which are used for creating competitive advantage with resources. 
Resource management involves:

1. Structuring: acquiring, accumulating and divesting resources.

2. Bundling for capability development: stabilizing, enriching, and pioneering resources.

3. Leveraging: mobilizing, coordinating, deploying strategies.

Deployment strategies involve looking for opportunities in: (1) resource advantage (2) markets (3) entrepreneurial activities.

Asset allocation was developed concurrent to resource management and it entails:

1. Search/selection: identification, investment, governance, organization structure, business model formation.

2. Configuration/deployment: providing vision, nurturing innovation, coordination of cospecialized assets.

\subsubsection{Lessons Learned: the Resource Based View}

The resource based view is very practical way to manage and operate a keystone or any organization. The resources are used to build the products and it is important to know what they are and how they complement each other for growth and strategy. Each member will bring resources to the keystone to contribute into deals in collaboration with other members. It is important to know the value proposition they bring to the platform and therefore into deals. It is important to have complementary resources and assets. Cospecialized assets are developed and members will learn and grow together. This will provide specialized assets for the keystone which are hard to imitate and are imperfectly mobile. 
To be successful, all the economic factors from Peteraf(1993) must be known and well managed at all times. The resource orchestration framework from Sirmon et al (2011) should be used to manage a keystone. There are resource management functions and asset allocation functions to be performed.

\subsection{Dynamic Capabilities}

The dynamic capabilities framework from Teece, Pisano and Shuen (1997) was developed partly because previous models for strategy management were inadequate in environments of rapid technological change. Dynamic capabilities build on the resource based perspective by explaining how combinations of competences and resources can be developed, deployed, and protected in response to changes in the environment. Whereas Porter's competitive forces framework for industrial strategy and the strategic conflict approach of strategy are focused on market power, the resource based view and dynamic capabilities are focused on market efficiency. Teece et al (1997) emphasize the importance of control over scarce resources because they are used to generate economic rents. Therefore skill acquisition, learning, and accumulation of organizational and intangible assets are important for strategy (Teece et al 1997: 514).

The following set of terms is useful for dynamic capabilities and the RBV:

1. Factors of production are non-firm specific components and available in factor markets. Examples include capital, land, unskilled labour, property rights etc.

2. Resources are firm specific assets which are inimitable, rare, or scarce, and are hard to transfer (immobile) between companies/industries because they are tacit. 
Examples may be trade secrets, production facilities, engineering design skills/knowledge, tacit knowledge or know-how.

3. Organizational routines/competences entail the use of resources by individuals or groups to carry out firm specific activities.

4. Core competences are central to the business of a firm/organization. The value of core competences can be enhanced by combination with complementary assets/resources (Teece et al 1997: 516).

5. Dynamic Capabilities are 'the firm's ability to integrate, build, and reconfigure internal and external competences to address rapidly changing environments.'

6. Products are the goods and services produced from activities using the competences and resources of the firm.

The performance of a firm's products compared to competitor products depends on the competences used to produce them which in turn depend on the capabilities. Use of the dynamic capabilities framework for strategic management involves identification of core competences and capabilities on which to build and improve and ensure they fulfill a customer need, they are hard to imitate and are hard to transfer out of the firm. It is also a strategic advantage to have competences and capabilities within a firm organization rather than in the open market. An open market is driven by incentives and contracts which are not conducive to cooperation and learning. Firm organization is orchestrated in a multi-lateral and decentralized fashion but with a 'viable headquarters operation' whereas an open market is governed by many bi-lateral contracts orchestrated by a coordinator. Entrepreneurs will not be able to easily replicate the capabilities and 
competences developed in a firm with a cooperative collaborative learning environment (Teece et al 1997: 517).

Thus, a firm's competitive advantage consists of the managerial/organizational processes, specific asset positions and paths available for it to take. The processes of an organization are routines, practices and ways of learning and doing things that were developed within the firm. Processes can be coordination/integration, learning, or reconfiguration activities and they are static, dynamic, and transformational respectively. It is important to note the management processes are distinct and are therefore strategic capabilities. The trend has been towards more external integration and coordination activities as firms establish more and more external alliances and partnerships. These are distinct from internal processes. As well, for rapid dynamically changing environments, a firm needs to build and learn efficient adaptable reconfiguration processes. To reduce costs it is an advantage to have decentralized autonomous control and decision-making as much as possible.

Positions are sets of resources (firm-specific assets) such as technology, knowledge and skills, intellectual property, complementary assets (resources), customer base and relationships with customers, suppliers and complementors (Teece et al 1997: 518). Assets for which there are no current markets are relevant to strategic competitive advantage. For strategic purposes therefore, it is important an organization have unique processes and asset positions to enable alternative strategic paths.

\subsubsection{Lessons Learned: Dynamic Capabilities}

It is important to develop dynamic capabilities in a keystone as a whole, and for its members and groups. Since it is based on the RBV, it is important to build the keystone 
based on this view. One must establish the core competences and enhance them with complementary assets and capabilities from members as the major strategy to use.

Deal-Making is the central important core process for the keystone and competence in it is important for all members and groups. It is important to have good software applications to facilitate the processes being used.

A flat open environment where members can organize easily but with some viable central orchestration should be more efficient than being on their own in a more competitive environment. Continuously manage the firm specific assets (resources), the complementary assets and strategically manage their growth for strategic paths.

\subsection{Stakeholder Management and Strategy}

As Rowley (1997) and Clarkson (1995) attest, Freeman (1984) brought together a number of concepts and principles to begin development of stakeholder theory as a way to describe and manage a firm. The definition of stakeholder in his book from 1984 "Strategic management: A stakeholder approach", still forms the basis of most meanings of the term used today (Rowley 1997: 889). Freeman (1984) defined a stakeholder as "any group or individual who can affect or is affected by the achievement of the organization's objectives". It implies the need to create wealth, value, and satisfaction for all stakeholder groups while pursuing one's own objectives (Clarkson 1995). Clarkson gave a narrower definition of stakeholder by saying a stakeholder bore an element of voluntary or involuntary risk in their relationship (stake) with a firm (Mitchell, Agle \& Wood 1997: 857). Voluntary stakeholders have some risk through their investment of some "capital, human or financial, something of value in the firm". 
Clarkson (1995) distinguishes primary and secondary groups of stakeholders. Freeman and others before this were only concerned with one set of groups. Clarkson (1995) defines a primary stakeholder group as being made up of members upon which the firm could not survive without their continued participation (Clarkson, 1995: 106). The primary group of stakeholders is made up of customers, employees, suppliers, shareholders, and investors plus public stakeholder groups consisting of government and community members. Secondary stakeholders are "those who influence or affect, or are influenced or affected by, the corporation, but they are not engaged in transactions with the corporation and are not essential for its survival." (Clarkson, 1995: 107). Managers are concerned with all the primary stakeholders not just the shareholders. They accept responsibility ensuring fairness in distribution of wealth and value created by the firm to all primary group members and ensuring their continued participation in the firm. No one group is to benefit at the expense of another.

Broad definitions of stakeholder result in power being the primary quality which managers use to decide whose concerns are to be addressed and in what order. More power means more legitimacy. Besides power, Mitchell, Agle and Wood (1997) argue that legitimacy and urgency are also essential attributes to consider when identifying stakeholders and their determining their saliency. These three qualities can be present alone or in combination with each other giving different traits with varying saliency. Urgency gives a dynamic quality to the manager-stakeholder relationship. Legitimacy is be based on factors such as contract, exchange, legal title/rights, moral rights, at-risk status, or moral interest in the harms and benefits of company actions 
(1997: 862). Urgency is the degree of call or demand for immediate attention to the claims of a stakeholder.

The managers of a firm/corporation/organization determine which stakeholders are salient and are to receive management attention (1997: 871). It is important for them to identify them correctly and their degree of salience according to how much power, legitimacy, and urgency they have. Manager perception is highly subjective for stakeholder attributes. Their role moderates the relationship of firm to stakeholder. It is essential to have as much accuracy as possible determining stakeholder type and salience and manage issues well and maintain the relationship.

If only one of power, legitimacy or urgency is present, it is a case of low salience. When two attributes are present in a stakeholder they have moderately high salience. If all three attributes are present, the stakeholder has high salience. The type of salience each attribute or combination of attributes maps to is shown in the table below. It is in the order from low to high salience type.

\begin{tabular}{|l|l|}
\hline Stakeholder Attribute Presence & Salience Type \\
\hline Power & Dormant \\
\hline Legitimacy & Discretionary \\
\hline Urgency & Demanding \\
\hline Power and Legitimacy & Dominant \\
\hline Legitimacy and Urgency & Dependent \\
\hline Urgency and Power & Dangerous \\
\hline Power and Legitimacy and Urgency & Definitive \\
\hline
\end{tabular}

Table 1 - Stakeholder Attributes to Salience Type Mappings 
When a stakeholder has power, legitimacy, and urgency, they have high salience, and are 'definitive' stakeholders. Their concerns have high priority and all issues and concerns must be addressed.

Dependent stakeholders have little or no power themselves and therefore they depend on the power of management to satisfy their concerns. They may get advocates or guardian groups to speak for them and protect their interests. They may also be able to get benevolence or volunteerism from a firm's management.

Dominant stakeholders have representation in governing boards. Traditionally, the dominant stakeholders are given high priority.

Dangerous stakeholders are not legitimate and could resort to threatening or destructive tactics to make their claims.

Definitive stakeholders have definite claims that must be addressed. The common problem in the past was in saying only the stockholders are important and always have priority over other stakeholders.

Coff (2010) asserts most approaches to rent appropriation are static: they (the stakeholders) exercise their bargaining power at a fixed time. Coff (2010) examines how capabilities and bargaining power evolve together (bargaining power varies with or depends on capability development). Lippman and Rumelt (2003a) say new coalitions may form as capabilities develop. Coff (2010) also argues some stakeholders will position themselves for value appropriation long before others know there is a capability being developed. However, there is no necessary relationship between ability to generate 
rent and ability to generate profit. For competitive advantage, Coff (2010) maintains it is better to have bargaining power for better performance.

Some stakeholders are individuals and some are groups. Coff (2010) states a stakeholder is an individual or group interested in generating a capability. A dynamic capability is 'a firm's capacity to deploy Resources, usually in combination, using organizational processes, to effect a desired end.'

Some rents are considered to be expense payments and are hard to notice. To measure total firm performance it is desirable to distinguish rent payments to stakeholders from amounts going to firm performance. Rent due to human capital (ability or knowledge) usually is claimed by residuals going to the owners. In a knowledge-based firm, individuals can be expected to have good bargaining power. Coff (2010) points out how cooperative game theory approaches of analysis take a static view of capabilities rather than a dynamic one. With a game theory perspective, the value of a capability is seen by its ability to enable a stakeholder to extract rent from its use and this is determined by alternative coalitions that may be formed. Stakeholders who are aware of knowledge asymmetries they have early in capability development may position themselves for rent appropriation early. Others may not even be aware of the value creation potential and hence not position themselves well for rent appropriation (Coff 2010: 714). Capabilities develop going through various stages of capability lifecycles, knowledge asymmetries occur, and it is therefore possible to see stakeholders becoming aware of their bargaining power with extra capability and positioning themselves to appropriate rent. Some may wish to join the nexus of stakeholders or they may be asked to join because of the resources they have. Some may leave the firm. Therefore the founders of 
an organization are compelled to be concerned with groups of stakeholders positioning themselves for rent appropriation, the value creation potential for the overall firm and benefit to other stakeholders in the organization.

Cable and Shane (1997) build on the answers to the question of how should entrepreneurs and venture capitalists structure their relationships to maximize mutual cooperation and minimize defection. The answer from past research indicates relevant inputs are: (1) Similarity of personal characteristics (i) demographics of work (ii) work values (iii) relative power (2) Information sharing (3) Time Pressures [schedule] (4) Amount of payoff for cooperation (5) Transaction procedures: (i) bonding mechanism(ii) staging of payouts (iii) generosity (iv) penalties for non-cooperativeness.

It has been known that a continued cooperative relationship between investor and entrepreneur is more important to the performance of the venture than the actual monetary investment.

Cable and Shane (1997) give a conceptual model of this relationship after the investment has been made and they show a cooperative relationship is necessary for its success. The relationship is non-hierarchical and more as that of being equal partners though they have the choice of cooperating or defecting.

The prisoner's dilemma is a suitable model. It is also good to show the dynamic nature of the relationship. Entrepreneur and venture are both interested in the success of the venture and this is an incentive to cooperate or a temptation to defect if the relationship is not one of mutual trust and openness or if one has self-interest over mutual gain. Indeed 
it is found that mutual cooperation is less prevalent than defection of the entrepreneur venture capitalist relationship (Cable \& Shane 1997: 147).

Each person has specialized knowledge which can give competitive advantage in developing different types of knowledge for the venture firm. There are many cases where companies will cooperate to gain monopoly power or economies of scale. This is another aspect but not of interest in this research on keystone organizations for making money.

The lack of an efficient market for venture capitalists and entrepreneurs leads to the need for cooperation. The venture capitalist has connections to investment sources needed by the start-up. The specialized knowledge of the entrepreneur means it is hard to find a replacement for him/her to develop and exploit the opportunity. Thus the need for venture capitalist and entrepreneur to cooperate is quite clear. In other business partnerships, the option to defect rather than cooperate is more easily chosen because replacements are readily available for the partner.

The Prisoners Dilemma is a metaphor that is often used to model social conflict in decision making between actors in sociological, economic, or political science settings. Actors have a choice to act according to self-interested goals at the expense of the group, or to act according to benefit of the group and potentially less for themselves. It's a decision to compete for individual gain or cooperate for mutual gain. See Axelrod and Dion (1988) for detailed explanation.

Reciprocity and trust are at stake: at each iteration/interaction, both parties know the previous decisions of the other and then decide how they will proceed. Despite nonfinancial benefits of attraction, the financial pay-outs are the primary attraction. Venture 
capitalists are attracted more if they have a larger ownership stake in the venture. This is relative to how much the venture capitalist already has. Entrepreneurs are more likely to cooperate because they have a lot at stake and not too much diversification - all they money may be tied up in their one venture. Generosity despite previous defections of the other side is a way to win back cooperation. It is not a tit-for-tat or eye-for-an-eye approach. Axelrod (1984) and Cable and Shane (1997: 165). Failure to be generous can be costly especially if one does not reciprocate generosity from generosity.

In a traditional business environment the coopetition framework (Brandenburger \& Nailbuff, 1998) is a way for a single company to sustain competitive advantage by cooperating and competing with members in the value network. It does so by changing its environment which can affect relationships of competition and cooperation with other members simultaneously. In so doing, it is a game theory game where the winner gets most points by way of profit. There are five or more elements that can be manipulated to control the game: players, added values, rules, tactics, and scope or links to other networks. Brandenburger and Nailbuff (1998) summarize how the game works with examples.

When a new member joins, it changes the overall value of the value net. When a new player wishes to participate, one asks the question 'which of the current participants has most to gain by this new member joining. They get to pay. The total value of a value network is equal to the sum of the values of each participant. A good way to add value is through improving relationships with customers. However, in a traditional model A business environment with simultaneous competition and cooperation some do better 
than others. There are definite winners and losers, and the rules of the game can be change as well as competitors try to throw each other off-guard and attract more customers. There are general rules to ensure a fair and openly competitive market. There are specific rules within a value network with contractual agreements between members. Various types of contracts can be used with customers such as most-favoured-customer contracts, or meet-the-competition contracts. Each has advantages and disadvantages which one must be aware of. For instance a most-favoured-customer may result in new customers getting better deals than 'most-favoured' ones and this can risk losing the customer, damaging the relationship, or preventing one from offering new customers better deals. Nevertheless, it may be a good way to retain customers in certain cases. There can be similar rules and contract types for supplier relationships all which have advantages and disadvantages but which are in common practice. In the open market, companies compete on price. If the price one offers is too low, a price war can break out and many may lose money and some may go out of business. Setting a price at the right level may be hard to do but one wants to make a profit and stay in business. Ideally, a seller wants to 'charge a low price to loyal customers without threatening a competitor's customer base'. A method of achieving that without much risk is a rebate program. Besides offering the opportunity of offering better services to customers, it offers the opportunity to work with partners who add value to the products.

Another way applying coopetition has to do with tactics - ways to change perceptions, or to create and clear confusion for other players in the value net. Perceptions are formed by the signals sent and received. The perceptions have to be managed. It will usually be best to clear up any confusion or doubts that exist by: 
- offering pay-for-performance style contracts

- offering meaningful guarantees on products or services

- offering free trials of products or services

- committing resources to advertising

To sustain false perceptions, which may still be good for the company, one should:

- not mention anything about projects not undertaken but which were successful for other parties

- follow the general opinion, play it safe so if everyone is wrong you don't look bad

- create reasons for failure which can be pointed at rather than having to explain why they arose

It's a good tactic to avoid the following:

- opening with bids that are too low and give no room to come down

- making threats which will ruin prospects of negotiations going favourably

Have a third-party intermediary present to handle negotiations.

Avoid arguments with negotiating parties by agreeing to disagree, or offer constructive criticism so it's a win-win situation for all in a negotiation/deal.

If one decides to tactically create a fog/confusion it is typically done with complex pricing schemes in the marketplace by such means as:

- Hiding low prices to give the impression of high quality

- Disguising situations of opportunistic pricing

- frustrating comparison shoppers 
One has to be careful creating fogs to deceive or confuse parties. They are expensive and they can be used against you. It's best to avoid them but beware of competitors using them.

\subsubsection{Lessons Learned}

- Groups of a keystone are stakeholders in the platform and must be managed accordingly.

- Keystone groups/sides are primary stakeholders with power and legitimacy. Governance structures must be set in place for stakeholder management and strategy.

- Keystone members have stakes in deals to which they bring an element of risk and value. They have legitimacy and power and may raise issues.

- Management and deal orchestrators must be aware of stakeholders and their saliency for the keystone and in Deals.

- Deal history can provide power and legitimacy as learning and capabilities grow for members.

- The orchestrator of a deal has a management role to play and must be aware of stakeholder saliency and fair/just outcomes for all participating members with stakes in the deal. Reciprocity and trust are desired qualities of the interactions.

- There are external dependent stakeholder groups to be aware of and maintain good relations with.

- Be benevolent to dependent members or groups outside the platform such as those with environmental concerns, students, mentoring, government relations on which a firm depends etc. 
- Stakeholders in a deal should use a static map of their stakes. They can change anytime. There is a need to prioritize concerns and be prepared for changes. Participant stakeholders may try to gain salience.

- Be aware of rent appropriation and capability development. Stakeholders with valuable resources deserve their share according to the value they bring to deals and the platform but it must be earned. One member must not profit at the expense of another's loss or lack of opportunity. Benefit of the overall keystone must be the highest priority.

- It is a primary goal for keystone members to develop capabilities together in cooperative and collaborative relationships. The keystone owner must be cognizant of capability development, knowledge asymmetries, and value creation potential. Be aware of stakeholder attempts to position themselves for better rent appropriation while others may not be aware of the potential value that can be created.

- Be aware of coopetition and the benefits of cooperation as well as competition. Brandenburger and Nailbuff (1998) provide principles and rules for coopetition. Some competition is good.

- Strive to have reciprocity and trust in relationships in DealMaking.

- The relationship between entrepreneur and venture capitalist is a model for investors in a keystone and it is also a model for any member in the keystone and in keystone deals.

\subsection{Summary of Lessons Learned}


The advantages of a keystone are well known and there are some very well-known examples of them to illustrate their unique manner of operating to generate benefits and growth for all (Iansiti \& Levien, 2004a, 2004b). Examples cited are usually keystones with a very large corporation as the operator. Often they are concerned with managing their go-to-market channel partners. Bailetti 2010 gives a blueprint for using the keystone approach to generate revenue for small companies. The benefits of having complementary groups (sides) with network effects of attraction are a central feature of building the platform for the operation of a keystone. Relationships between sides and members built on mutual cooperation and collaboration is obviously essential.

Relationship management is therefore important.

The Resource Based View (RBV) enables the keystone operator to view potential for complementary resources, capabilities, and assets to attract members and build a cohesive platform based on complementarities, learning, and collaboration in product or service development, and growth in capabilities (Peteraf 1993; Teece 2007). These are essential for the governance and strategic management of the keystone. What is seen as an essential and strategic capability for revenue growth in a keystone ecosystem is dealmaking as it will be the means for members to produce economic rents, not to simply break-even or sustain production through efficient processes (Lado, Boyd, \& Hanlon 1997; Brandenburger \& Nailbuff 1998; Gnyawali, He, \& Madhavan 2006). With the open, cooperative, and collaborative approach (with competition as well for generating rents), a deal-making process is suitably designed to enhance these qualities and methods. Customer relationship management (CRM) systems have been long in-use to manage relationships between a single firm and its customers although it has been primarily 
through interactions with sales and marketing teams. Their integration with social network sites are a common practice as well and this enables the company to relate social connections and network effects with the relationships to the company through sales and marketing activities. To emphasize, this is to generate revenue for the single company through sales to its customers.

Principles from circular design (Romme \& Endenburgh 1996) with positive feedback loops are employed to get feedback on capabilities and to be able to promote selforganization for improvement of the processes, member and platform health. Since this thesis describes the construction of a keystone, starting and monitoring its operation, principles from the above theoretical research areas which are well understood and applied for firms can be used for principles and rules for a keystone for making money. Being built with a disciplined design approach with intelligent monitoring capabilities will instill confidence.

Stakeholder Theory provides a sound basis on which to identify stakeholders and stakeholder groups and to manage them. It can be applied to management and governance of the platform. The stakeholders are its members and the groups are the sides. Similarly, a deal has stakeholders each with individual stakes and salience to be managed. 


\section{Chapter 3. Research Method}

Table 2 shows the steps and dominant activities carried out to achieve the deliverables.

\begin{tabular}{|c|c|}
\hline Step & Dominant Activity \\
\hline $\begin{array}{l}\text { 1. Preliminary data } \\
\text { gathering, analysis, } \\
\text { planning: CRM } \\
\text { Selection }\end{array}$ & $\begin{array}{l}\text { - Analysis of common single company CRM functions and } \\
\text { components. } \\
\text { - Preliminary modeling a keystone ecosystem as a MSP } \\
\text { using components in the CRM } \\
\text { - Preliminary design of a collaborative multi-sided deal } \\
\text { making process } \\
\text { - Comparison of single-sided company sales to a multi- } \\
\text { sided keystone deal making processes. } \\
\text { - Preliminary identification of work items. } \\
\text { - Demos and discussion with lead deal making process } \\
\text { group, the keystone sponsor. } \\
\text { - Selection of an open source CRM as a tool and } \\
\text { framework to build with. }\end{array}$ \\
\hline 2. Prototype & $\begin{array}{l}\text { - Create plan of activities and functions to address first and } \\
\text { in what order. } \\
\text { - Iterative design method with successive improvements on } \\
\text { prototypes. Coordination between deal making process } \\
\text { development and multi-sided platform keystone } \\
\text { ecosystem development using the CRM. } \\
\text { - Project group formation, partitioning and plan of work } \\
\text { items. } \\
\text { - Reporting and monitoring of issues, code and } \\
\text { - Interamentation management set up. } \\
\text { - Development, test and integration. } \\
\text { - Iterations and improvements. }\end{array}$ \\
\hline $\begin{array}{ll}\text { 3. } & \text { Production Quality } \\
\text { Solutions }\end{array}$ & $\begin{array}{l}\text { - Iteratively build and improve prototypes to arrive at one } \\
\text { suitable for production which was stable and good enough } \\
\text { to start with. } \\
\text { - Usage and performance monitoring and support functions. } \\
\text { - Plans for future evolution. }\end{array}$ \\
\hline
\end{tabular}

Table 2 - Outline of basic steps to achieve Deliverables 


\subsection{Method for Step 1-CRM Selection}

Much of the preliminary steps are for team organization. The prime goal for step 1 is selection of an open source CRM to build a multi-sided platform for enabling deal making for a keystone ecosystem of companies. The method for this selection is discussed here.

CRM technology was chosen because it supports relationship management processes for sales and sales and marketing teams. The platform is multi-sided rather than two sided but CRMs support the concept of customer and company sides and groups which are still required in a keystone.

Deal-Making in a keystone is similar to a single 'model A' company sale though it requires support for multi-sided deals and a different process for collaboration and value creation than a single company sale. Not using an existing CRM base to build on would involve a longer development time since there would be less reusable base components to build on. On the other hand, building components from scratch gives more options for customization with less coupling to the existing base framework. It also gives more ownership and independence of product.

The benefits of using open source include: (1) an existing base to build on (2) support of an extensive community (3) access to the software to change and modify (4) flexible and open licensing options for reuse with options for entrepreneurial endeavor.

\subsection{Method for Step 2: Prototyping}

The aim of building the first prototype is to learn and gain experience with the tools and development environment and produce a simple model that would suit some of the initial 
requirements. It is hoped that it would quick evaluation and change our mind early about decisions in step 1 if necessary.

Magaña and Whitehead (2010) advise choosing CRM technology to support business processes and incrementally add more as they are needed. It is necessary to evaluate which ones are needed for a multi-sided platform keystone ecosystem with deal enablement.

Use an Object Oriented Design to come up with a class model with maximum re-use of components supplied by the selected CRM. Build on the framework it provides and add to it whatever is required for a minimum system that can be customized and extended to suit different types of keystone ecosystems with different types of deals. Build into the components attributes to support the readings in various theoretical areas.

Design for the multi-sided platform: a Keystone which consists of two or more sides or groups of company members. Apply the theory of keystones where each company joining has a value proposition to the platform in the form of resources and capabilities it offers. Members on a common side have resources, capabilities and assets which are similar and which complement other sides.

Design for deal making process: support the concept of a deal with multiple dimensions which have to be voted on and agreed to for deal completion. Deals are flat in the sense that each participant has equal weight in voting on dimensions. Gates are made of dimensions. Gates are time durations. If the dimensions are not agreed to for a gate, then the gate is not passed and the deal is closed. Members may be invited to join or they may ask to join. Members may raise issues for dimensions and have to deal with them to 
complete the gate and the deal. Members rate each other at the end of the deal. Ratings are a way of giving feedback for improvement.

\subsection{Method for Step 3: Production Quality}

Build successive prototypes with improvements each time till one is arrived at which is of high enough quality for production use. More ideas from the literature review are added each iteration as well as improvements to the design based on previous exercise in prototyping.

Production quality requires factors to consider consist of:

1. Completeness in terms of all use cases can be successfully executed for requirements. All of the user and system administration level interfaces work.

2. Reliability: no major errors seen in exercise and testing of all use cases. All major problems have been solved.

3. Easy to install and operate from a customer user perspective (usability).

4. Upgrades and backups of the database can be performed easily.

5. The system can be scaled to support large numbers of users and their data operating over time.

\section{Chapter 4. Results}

Chapter 4 describes the outcome from completing each of the construction/design steps outlined in the previous chapter on method.

\subsection{Outcome of Step 1 - Open Source CRM Selection}

There were several open source CRM possibilities to choose from. The main choices were vtiger, SugarCRM (Sugar), and openCRX. Deciding factors were: (1) familiarity with tools or framework (2) open source licensing (3) implementation language (4) 
ability to extend and modify (customization) (5) available packages and plug-in system (6) size and complexity (learning curve) (7) security (8) web-services API support. vtiger is a fork off SugarCRM. Therefore, they are similar. There was familiarity and experience with vtiger and SugarCRM and this was an important consideration since time available to design and develop was short. It was easy to install and trail the use of either CRM.

vtiger has support for product inventory management and quotes and invoices while Sugar does not. On the other hand Sugar has many other features which vtiger does not have. It was not clear whether or not we would need inventory management or quotes and invoices for a Keystone.

OpenCRX is a truly open source project but with support from a large number of companies which have businesses based on the open source. Sugar and vtiger are owned by companies with commercial versions through which they generate revenue. Unfamiliarity with openCRX, its apparent size and complexity, and the learning curve required to get started led the researcher to reject it. Vtiger and Sugar are both suitable for small to medium sized businesses and this was desirable for this research project. vtiger has the Mozilla Public License (MPL) and sugar has the GNU Affero General Public License Version 3 (AGPL). The MPL license is regarded by the Open Source Initiative organization (opensource.org) as more popular and 'widely used by strong communities'. The AGPL license is an 'uncategorized license' and the software that is used or modified must be distributed for free use and access by others and the software must keep the AGPL license. The AGPL license was therefore deemed to be less advantageous than the Mozilla Public License for using the product for entrepreneurial 
venture. Despite the license issue, SugarCRM open source seemed to have an advantage for this research project because it had:

- an active community that seems to be larger than that of vtiger

- a plug-in system with many free packages to choose from

- visual tools to customize and create new modules

- web-services API support for SOAP or REST interfaces

- good security support with the Resource Based Access Control method for module data access and extra plug-ins for security teams

- Sugar has a UI that looked more appealing, modern and had high usability.

\subsection{Outcome of Step 2 -- Prototyping}

A single company sales process evolved into a multi-sided deal-making process for a keystone. The sugar modules were not altered but a new package for a keystone ecosystem to make money through deals was created. A simplified model of components and their relationships in a typical CRM is given in the figure below. 


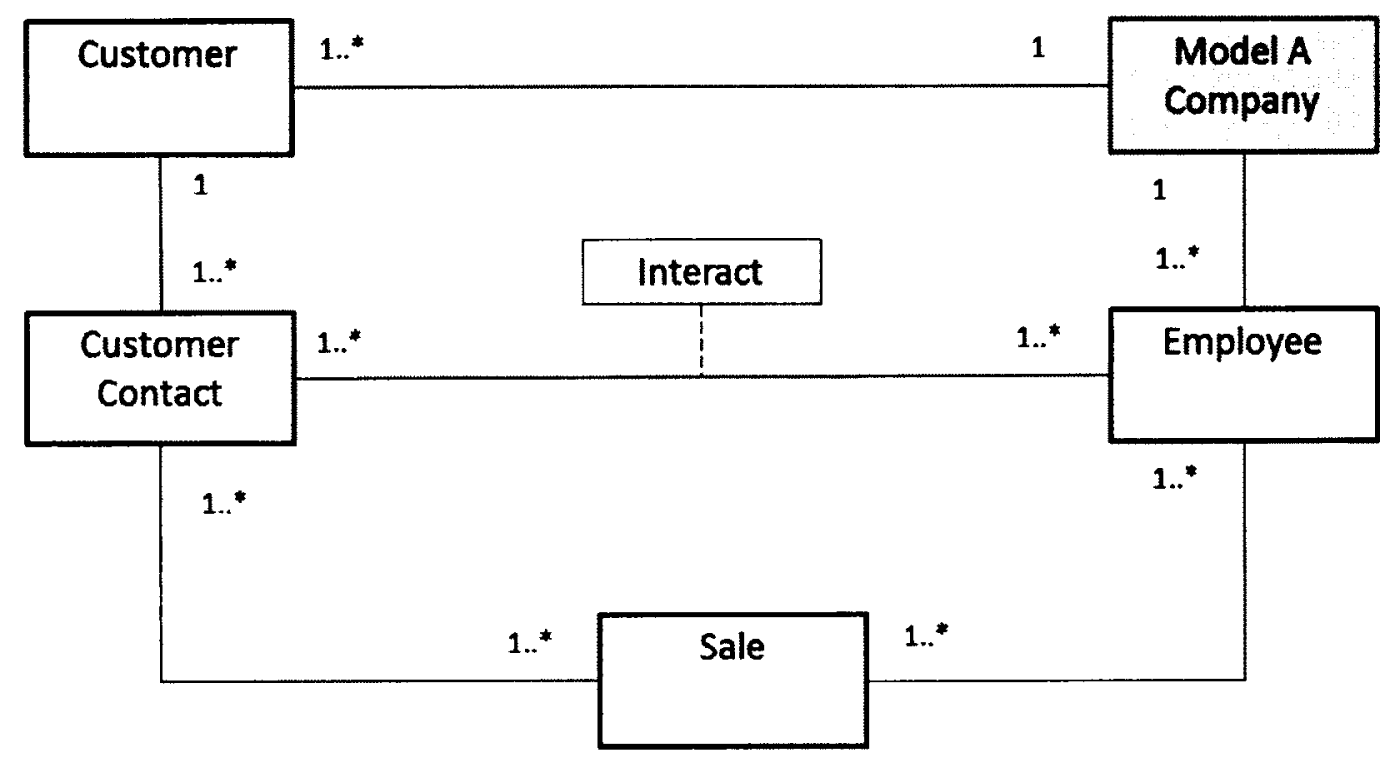

Figure 3 - Single 'model $A^{\prime}$ ' company sales in a typical CRM system

An interpretation of the diagram in the above figure is as follows. The company has one or more customers and one or more employees. Each customer has a number of customer contacts which employees interact with using various tools and modes of interaction. These interactions are typically to process leads and opportunities and eventually to make sales to the customers. There could be email exchanges, telephone calls, meetings, project management activities, and task management but these need not be shown for understanding the use-case. They are simply all ways of interacting leading to a sale or creating value for the company and the customer. Employees typically belong to the company's sales and marketing teams and there are well defined processes to follow leading up to the sale. Sales are the goal but the transactions are relationship oriented. 
Some companies could be transaction oriented sales, with no lasting relationship, or with a view towards recurring sales but the relationship transaction subsumes recurring sales because of the relationships being maintained and built up.

Evolution of a CRM to support a model $\mathrm{C}$ keystone with deals came from design principles from Bailetti (2010). The platform is created with a number of sides or member classes, there a number of members per class, and a price structure set. A highlevel diagram of the components for a keystone ecosystem to provide that support is given below:

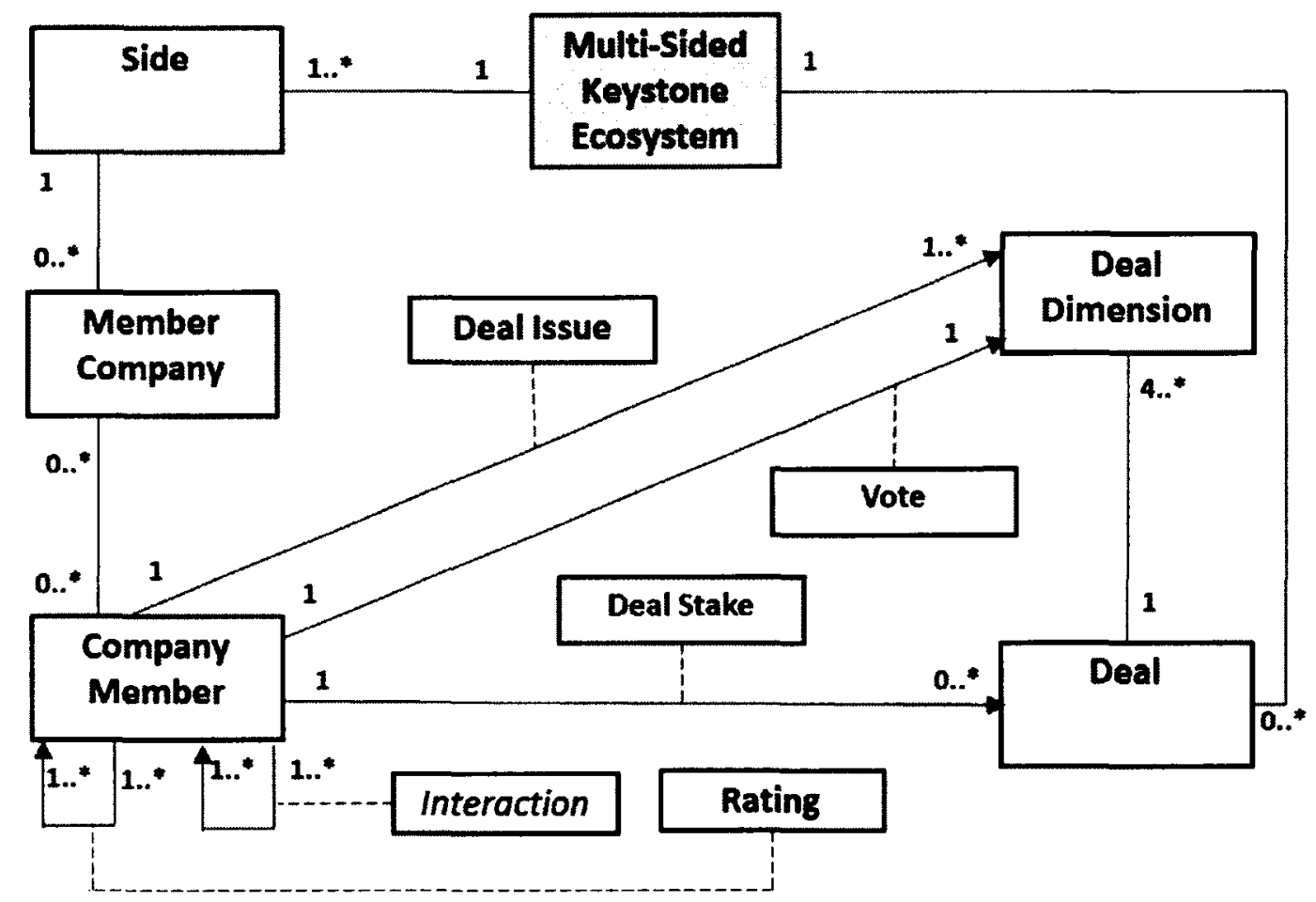

Figure 4 - Minimum Value Platform of a MSP keystone ecosystem with Deal-Making 
A keystone ecosystem is made up of more than one side or classes. One or more sides could be customer groups. Each side is made up of a number of member companies each of which has one or more employees.

Members in a group/side have attributes in common typically because of the resources and capabilities or assets they bring to the platform.

The remaining components relate to deal-making. There are no deals when the platform is created and while members are joining. They grow when the platform is operating and members make deals together. A deal has multiple dimensions. Members are associated with the deal through stakes. Stakes include the role they have in the deal, their value proposition, and the money or values they receive from the Deal. The members interact with each other and vote on the dimensions. They raise issues against dimensions and they will have to resolve the issues before closing the deal. One of the dimensions is a time dimension which identifies gates for agreement on subsets of dimensions. If there is a timeout, the deal is cancelled. If all dimensions are agreed to, signified by votes, before the timeout, then the deal is completed. At the end of the deal, members rate one another. The Deal Stake is an association class which has attributes about the association between Keystone members and the Deal. A keystone member can be participating in more than one Deal at a time. Each participant in a deal has a stake which connects the keystone member to the deal and hence other participating members in that deal. They must all complement one another. It is also possible for a member to switch companies or to belong to more than one company. 
Below is a nested state machine for DealMaking using the above objects/modules:
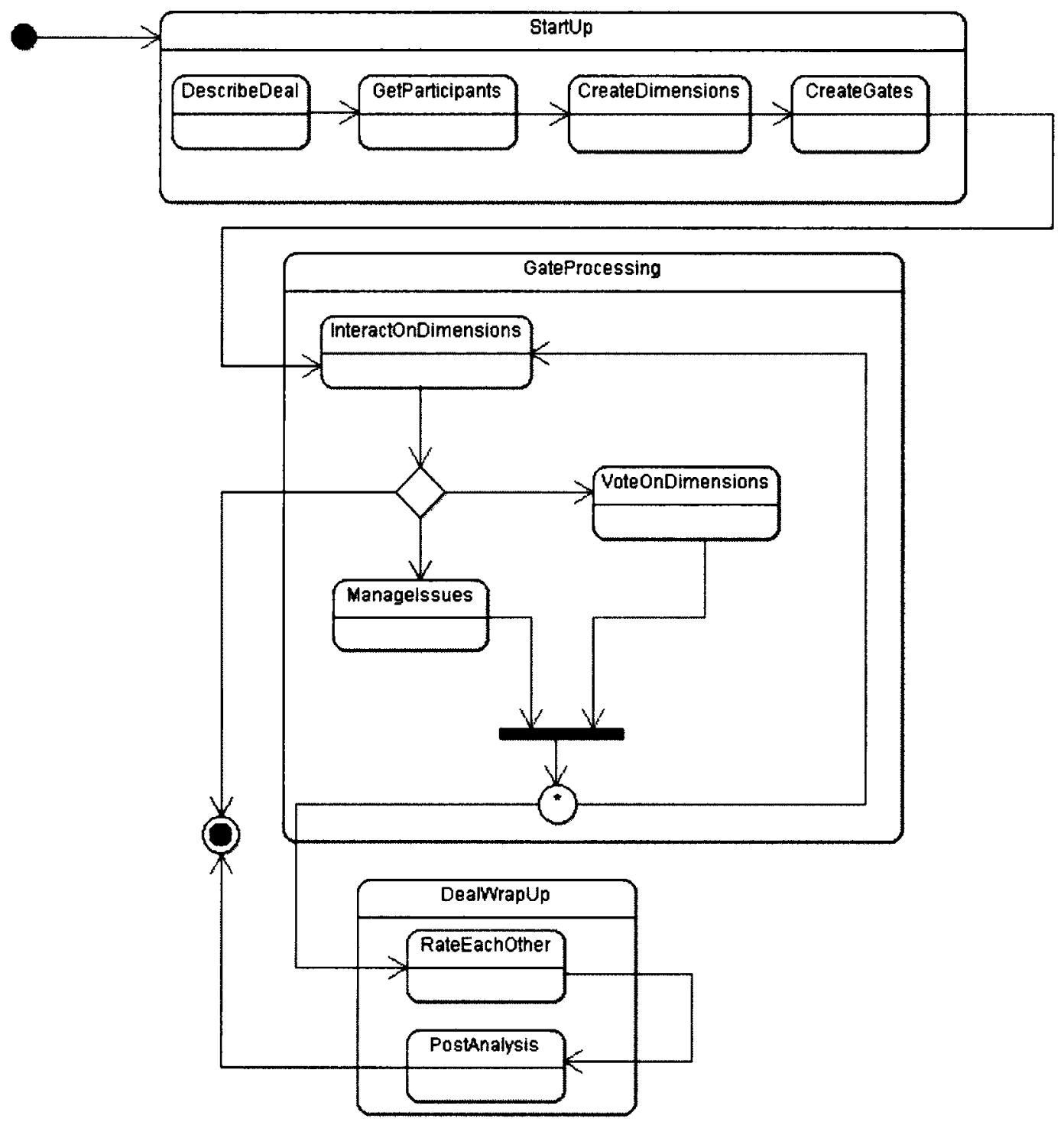

Figure 5 - State-Machine for Keystone Deal-Making

Below is a walkthrough of the actions and transitions for deal-making.

1. Start_Up: 
a. Sub-state DescribeDeal: A Deal is created and its description and all other data fields are provided. The deal then transitions to sub-state GetParticipants.

b. Sub-state GetParticipants: The creator of the deal is in charge and his/her role is that of the orchestrator. This may also be the customer with a customer role or an orchestrator may be asked to join. Participants (Keystone Members / Deal_Delegates) are sought based on the resources and capabilities they can bring into the deal. They may also offer to join. There could therefore be some competition between participants with similar capabilities vying for participation in the deal. The description of the deal, its requirements are also used to guide. When members join a deal, they are assigned roles as well as other attributes in their stake related to their value proposition, risk, and what they hope to gain. Members may leave or be asked to leave by the orchestrator and new members may be brought in anytime. The stakes can change as the dimensions of the deal are defined and collaboration takes place.

c. Sub-state CreateDimensions: The next task is to create all the deal dimensions. The minimal set is Objectives, TimeLine, and Amount but Additional Dimensions may be added. There is a good deal of discussion and various types of interaction taking place when dimensions are created and agreed upon.

d. Sub-state CreateGates: At this time, the timelines are set for the major gates of the deal. The dimensions for a gate must be all passed before the 
gate expires or the deal is cancelled. Therefore setting the gates is important.

2. GateProcessing: This is the state where a lot of interaction takes place and the deal advances as dimensions are agreed on. Members can vote anytime and raise issues. Issue management also takes place. As dimensions are agreed, the gates will be passed, or if there is no agreement at the time of the gate closing, the deal is off. When all dimensions are agreed on, all gates have passed, and all issues are resolved, the deal GateProcessing is over.

3. DealWrapUp: Participants rate one another. A PostAnalysis is also done. Details of what this is are not defined but it has the intention of wrapping up, getting closure and sharing ideas for improvement in the future. Information is intended to be captured for feedback. There could be contracts that have to be formed based on the agreements made on the dimensions and project plans to be made if that has not already been done as one of the dimensions. It is expected that feedback from experience and deal history, will provide useful data for process improvement.

For an indication of the types of problems seen while testing the various prototypes, Appendix B contains the list of bugs seen while testing the last two prototypes.

\subsubsection{Implementation Details}

The set of business processes given by Magaña and Whitehead (2010) that must be considered from Sugar and my decision and reasons are shown in the table below:

\begin{tabular}{|l|l|}
\hline CRM Process & Applicability for a Keystone for making money \\
\hline $\begin{array}{l}\text { Account and Contact } \\
\text { Management }\end{array}$ & $\begin{array}{l}\text { Yes, but decided to build our own custom Account for Deal- } \\
\text { Making to avoid problems with Sugar upgrades. Can use Contacts } \\
\text { but associate them with Deal Accounts. }\end{array}$ \\
\hline
\end{tabular}




\begin{tabular}{|c|c|}
\hline $\begin{array}{l}\text { Lead and Opportunity } \\
\text { Management }\end{array}$ & $\begin{array}{l}\text { Yes, Partially. Keystone owner/operator has a need to get new } \\
\text { members to join. This is like lead and opportunity management. } \\
\text { Not using Lead and Opportunities modules initially. An } \\
\text { opportunity can be incorporated into a Deal in the future. Using } \\
\text { the Sugar Account would go well with using Sugar Lead and } \\
\text { Opportunity modules. They could be related to Deal_Accounts in } \\
\text { the future. }\end{array}$ \\
\hline Sales Force Automation & $\begin{array}{l}\text { No. Though a keystone is to enable deals to make money } \\
\text { collaboratively from within and this is to be tracked. }\end{array}$ \\
\hline Sales Analytics & Yes, but we want Deal Analytics and it requires custom work. \\
\hline Customer Service and Contracts & $\begin{array}{l}\text { Yes. Can have a Deal to make a contract for customer service and } \\
\text { manage as recommended similar to how it's done in Sugar } \\
\text { (Magaña \& Whitehead 2010:39) - a Project associated with a } \\
\text { Customer Account and a Deal associated with the Project. }\end{array}$ \\
\hline Knowledge Management & $\begin{array}{l}\text { Yes. Essential to capture knowledge (tacit knowledge) in the } \\
\text { keystone. Use mechanisms provided by Sugar open source } \\
\text { framework, the Document module and its version control. }\end{array}$ \\
\hline Activity Management & $\begin{array}{l}\text { Yes. Use a subset of activities from Sugar and associate them with } \\
\text { a Deal or Deal_Account. Tasks, Meetings, and Projects can be } \\
\text { used in a Keystone. New types of interaction tools and } \\
\text { capabilities will be developed for deal-making or simply } \\
\text { collaboration and discussion. }\end{array}$ \\
\hline Email Management & Yes. Email is part of the open source package. \\
\hline Marketing Automation & $\begin{array}{l}\text { No. There may be a need to do marketing for external customers } \\
\text { besides internal keystone customers. There could be lead and } \\
\text { opportunity management and via a web-interface as well as other } \\
\text { means of communication by channel processes. }\end{array}$ \\
\hline Employee Directory & $\begin{array}{l}\text { Yes. It's part of the open source package. All members of the } \\
\text { keystone are considered employees when the register. }\end{array}$ \\
\hline Interface Consolidation & $\begin{array}{l}\text { Yes, but omit for first product release. These are possibilities for } \\
\text { the future. It is popular but not crucial to start. }\end{array}$ \\
\hline Document Management & $\begin{array}{l}\text { Yes. Accounts and Deals should have Documents associated with } \\
\text { them just as Sugar Accounts and Activities have Documents. } \\
\text { Keystone Knowledgement will use Documents. }\end{array}$ \\
\hline Reporting Analytics & $\begin{array}{l}\text { Yes. But by not using existing Sugar modules for monitoring the } \\
\text { sales pipeline, custom work has to be done to get Deal analytics. } \\
\text { Using existing Sugar modules would have provided analytical } \\
\text { reports for them. }\end{array}$ \\
\hline
\end{tabular}

Table 3 - Business process support for a keystone ecosystem with Deal-Making

In addition to the major set of CRM functionality in the table above, there are few minor

ones that were considered as well.

1) Instead of sales teams and regions, we have the concept of Deal Teams or groups. 
- Sugar provides means of managing groups though Deal-Making has members connected to one another through their stakes in the deal. More concern was given to access privileges for groups and individuals.

2) Product catalog management, sales inventory, corporate assets, and client products covered by support assets.

- These were omitted for the research project but it was thought highly possible that they would be needed for some keystones. Keystone members bring resources and capabilities to the keystone and more are built as a result of Deals. Tracking them should be important but it was not considered for the initial product.

3) Client quotes and contracts: It was thought that a quote would always be an output of a deal and possibly a contract would be as well. Vtiger has modules specifically to support them.

The design was split into two areas: (1) creating the multi-sided platform for a keystone (2) creating the deal-making set of modules for deal-making activities. Sugar has a set of module templates which can be used to build common modules required for CRM functionality (Sugar Community Edition 6.0 Documentation): Basic, Company, File, Issue, Person, Sale.

Each Keystone Deal-Making module typically had many attributes and associations added to them to incorporate the concepts from the literature reviewed and provide the functionality desired. The modules, their attributes and associations grew and changed with each prototype. Evolution of the Deal-Making process had the most number of 
changes. Creating the platform with its sides and members using concepts and principles from the resource based theory was completed first and remained fairly stable. Several dropdown lists were added for use in the modules attribute definitions. All of the Sugar dropdown lists can be customized to suit different keystones. Dropdown lists are important for analytics because they have discreet values to track on. Sugar provides a special graphical tool to work with them. Deal_Account_Types list was taken from the Sugar Account_Types list. It became obvious the account types were a mixture of stakeholder types and channel partner types and theoretically the list could grow if we wanted a superset. For the prototypes, Stakeholder_Types are almost the same as the Deal_Account_Types so this suggests only one of them may be needed or we create a customized list for each keystone. In the use cases, the Account_Types or Stakeholder_Types are used to decide which side a member belongs to and it is also used the stake they have in deals. It became clear that the list of account/stakeholder types should be customized to suit a specific keystone. This rule applies for other data-types as well.

Relationships between modules are significant and required special attention to define. Sugar provides good support in visual tools for working with modules and relationships are part of them. Sugar supports one-to-one, one-to-many, or many-to-many relationships. These are the only attributes of a relationship that Sugar maintains. Since relationships show the associations between modules, the UML class model had for the Keystone platform to match the view of associations between objects in a Keystone. When incorporated with the classes needed for a Deal to make money, the relationships had to relate to relationships during the process/workflow for a Deal. 
It was easy to create the Keystone model with one or more Platform_Sides, one or more Deal_Delegates per Platform_Side and one or more Contacts per Platform_Side. The relationship model was simple for the Deal: A Deal has four or more Deal_Dimensions; zero or more sugar Tasks, Calls, Meetings, Documents, Notes, and Projects. A Dimension can have zero or more Deal_Issues, and Deal_Votes. To connect a Deal_Delegate to a Deal, a Deal_Stake was needed and logically it should be an association object with attributes of the relationship between the Deal and the Deal_Delegate. Sugar does not support association classes so something had to be done to solve this problem. A Deal_Stake module/class was made to appear to have properties of an association class. It had stake-like attributes for the value proposition: what the Deal_Delegate was bringing into the deal to create value and what the delegate hoped to gain from it. The role in the deal was also given though it is related to the stake in the deal which comes through the resources or capabilities of the Deal_Delegate. A Deal can have multiple Deal_Stakes, one per Deal_Delegate (it would be unusual to have a person with two stakes in a deal transaction so it was left out). A Deal_Delegate can have more than one Deal_Stake being involved in more than one Deal. A simplified graphical representation is as follows: 


\begin{tabular}{|l|l|l|l|l|l|}
\hline Deal_Account 1 & $0 . .^{*}$ & Deal Stake & Deal \\
\cline { 2 - 4 } & & $\begin{array}{l}\text { Deal Role } \\
\text { Value Proposition } \\
\text { Stakeholder Type } \\
\text { Amount }\end{array}$ \\
\hline
\end{tabular}

Figure 6 - Deal Stakes as association objects associating company members to deals.

Thus the stakes connect keystone members into deals. From a Deal, we can always get all stakeholders in it and from a Deal_Account, we can find all the Deals they are or have been involved in and what their stakes were in each one. The stakeholders in a Deal are also similar to a stakeholder group and with the relationships in sugar, we can monitor and track performance of deal groups over time. This was not attempted for the prototyping but the aim was to determine the module structure and relationships that would be needed for that important CRM functionality in the future.

It was a similar procedure to implement an association-like module/class for Deal_Votes which relate Deal_Delegates to Deal_Dimensions they vote on. Similarly for Deal_Issues they may raise against Deal_Dimensions. Deal_Ratings are association-like 
classes for Deal_Delegates between one another in a Deal. They give ratings for each other at the end of the deal.

Iterative development of prototypes resulted in development and test of use cases: creating the platform, having members join, and the deal-making process. In the process of testing, it was verified instances of all objects/modules could be created, all fields were correct and could be set, all relationships were correct, database tables were consistent with the displays for each module. A number of administration use cases in sugar were exercised as part of application installation and maintenance.

At the application level, the deal-making process is the most significant use case for a member besides joining the platform. It is explained in terms of interactions and roles of participant members, their stakes with value propositions, resource, capabilities and assets they bring to the platform for use and development and making money through deals with others.

\subsection{Outcome of Step 3 - Production Quality}

The model was successively refined with the addition of modules, attributes and relationships till one was decided to be good enough for a general framework for building a keystone to make money. The goal was to be decoupled from sugar as much as possible in order to lessen the impact of changes in sugar upgrades and to make it easy to deploy the package in new installations, and to maintain them.

There were some crucial administration use cases (functions) in sugar that had to be tested to become a deployable product: (1) package publishing (2) package installation in 
new releases of SugarCRM Community Edition (SugarCE) (3) managing customizations and storage in a repository (4) performing sugar upgrades.

1) Publishing and Installing Packages: Sugar procedures were followed for publishing the Keystone package. There were errors seen when the first package version was installed:

a) Dropdown lists were missing

b) Missing relationship tables for modules on one side of the stake and ratings modules.

These problems took a very long time to debug and fix. There was some help from the development groups in sugar but most had to be done by myself. The way the dropdowns were created, using the visual tool in the earlier version of SugarCE, may have been the problem. To know for sure, the entire package would have had to be rebuilt and this is very time-consuming so the manual procedures to fix the problems were fully documented. It was fairly simple to fix all the dropdowns manually in a newly deployed package so it was decided to stick with this solution for the first version.

Missing relationship tables was a very difficult problem. The most likely reason for this happing was the names of the modules were too long but to verify, I would have had to rebuild the package. Instead, I documented the manual procedures for fixing the code in the package, and thus making a newly corrected package. Installing the corrected package was verified to work.

2) Sugar Upgrades: The use case is to be able to apply a sugar upgrade on an instance where the Keystone package is installed and for which data exists. Procedures are 
well documented in Sugar and they have to be followed exactly. As with package publishing and installation, it takes practice but it's very necessary for being able to deploy and support a product. On a live site, this is typically done on a backup application in case there are problems. Once the upgrade is done and any problems are fixed, the backup application instance is made to be the running application and the other instance is upgraded in a similar manner. Database backups have to always be done lest any data is lost.

3) Documentation: Extensive logs and notes were documented for all the prototypes and models. The UML modeling in ArgoUML was most valuable and represents the major set of documentation besides the methods and procedures for doing things such as common problems to be fixed. 


\section{Chapter 5. Discussion of Results}

Selecting the SugarCRM Community Edition to build on was done fairly quickly and going into the prototyping stage there were several questions to be answered:

1. What problems would result from using open source from a company that wants users to switch to its commercial version? It was expected to have to work with the source in order to learn to use it, get it to work properly, customize it, and fix bugs along the way. Things didn't always work as expected. Problems were difficult to solve sometimes. There was good support from the community but I still had to do a significant amount of work on my own fixing bugs. Towards the end of the term, SugarCRM made some improvements in how they manage the community and it seems to be making an improvement. John Mertic, who wrote "The definitive Guide to SugarCRM" (Mertic 2010), was chosen to lead the open source community and a number of good changes were made with the new leadership. It was a good sign the company was placing importance on its open source version. The Forrester report from Band (2012) attests to that as well. SugarCE was put into GitHub and the source is more readily available for community participation. I documented all the problems and their solutions to use for the future and I found it was good to have this personal documentation of issues for myself to reference.

2. Did we make the right choice with a CRM? Would it have been better to write all our own software and set our own license though we'd have more software to write and not be able to reuse a lot of free packages? 
In the end I believe we made the right choice. One of the goals was to change an open source CRM to enable it to be used for Keystone management and to support deals, but this could have been done without an existing CRM.

It was important to decide what to use from Sugar and what to add to it. Anyone deciding to use CRM technology to support their business should follow steps as outlined by Magaña and Whitehead (2010: chapter 2) matching CRM functionality to business needs. Bain (2012) indicates the SugarCRM open source version is an important factor of the company's success. Vtiger wasn't on the list.

3. How difficult would it be to provide the new package built for Keystone DealMaking as an extension to the Sugar platform ${ }^{\mathrm{ii}}$ ? This is a future possibility. It would definitely be unique as there is no other such offering available for Sugar. There were only two commercial applications which were found to support channel management and they used the word 'deal' in the package name. These applications are extensions to existing CRMs. One is Channeltivity ${ }^{\mathrm{iii}}$ and it is described as a partner relationship management system. It is similar to dealmaking but it appears the company who owns it has most power and is probably very much in control of the channel member partners in this type of deal-making. It's not a keystone environment. It is a model A company working with its channel partners to deliver to its customers. A larger PRM supplier is RelayWare $^{\text {iv }}$ and its application is also for managing deals with channel partners for a single model A company. An open source multi-sided platform Keystone for making money through deals is unique from this research.

4. Would it be hard to build an entrepreneurial opportunity? 
This is still an option that could be pursued but there could be roadblocks from the commercial company that controls the platform. The open source AGPL license may be a problem.

5. Would we be impacted by changes to base open source software we're building on?

If one changes the existing modules in the SugarCRM framework, one has to be very careful doing upgrades to the modules. Custom changes have to be managed separately from the base. After upgrading Sugar modules, the customizations have to be merged to the Sugar modules to which they belong. To decouple our software from the open source modules provided, it was decided to not modify sugar modules and build new custom ones that were sub-classed from the basic templates. Template modules were extended rather than modified. The disadvantage of this approach is it would be hard to convert existing Sugar users who use the sugar Account module and do Lead and Opportunity management into a keystone. It's a possible opportunity for the future to explore a different design which uses the sugar Account module instead of the Deal_Account and add customizations to it.

6. How could we make money from a business if the open source has the AGPL license and we have to publish the source?

Sugar customizations are harder to manage and we wanted many new features in the user interface for Deal-Making. To get around this problem, the Deal-Making application process user interface (UI) was built in an entirely different framework, Django. Users can use the UI in the Django Deal-Making 
application. Keystone ecosystem platform management is done in Sugar to begin and create the MSP but in the future it can also be done through the Django interface application. The Django application controls the workflow so no workflow is implemented in Sugar unless a stand-alone version is wanted. The Django application could use the Sugar APIs for access to all the Sugar Modules and the module data would all go into the sugar database. As we went forward into the prototyping, keeping the Django Application and the sugar modules in sync was difficult and required a lot of work. Likewise, using the SOAP APIs was more work than expected and proved to be difficult to implement. Real-time performance was also slow using the SOAP APIs.

Even if the source code is published and made available to anyone, it would be hard for them to understand how to build and manage a multi-sided platform keystone if they don't understand the principles behind it and how to operate in a model $\mathrm{C}$ business model environment with multi-sided deals.

7. How much of the Sugar functionality do we need to start or would we ever benefit from it using them?

This is the classic question of using CRM technology to support relationship processes. The lesson learned from research was to use the technology to assist with your processes and grow from there. It therefore had to be decided what functionality we need and what we don't need, and develop what's needed for a Keystone to make money through deals. The decision was to start simply and focus on creating: (1) the platform with members on sides (2) component modules/classes for the Deal-Making process and (3) the workflow to control the 
Deal-Making process. Further guidance for implementing a CRM for a model A company can be obtained from Magaña and Whitehead (2010: chapter 2).

Prototyping was necessary for learning and discovering what could be done. Each model built on the learning of the previous one. Learning the tool was necessary but learning the theory and applying it into the model was also a big challenge and it was crucial for this research. It was believed that a system or product built on sound theoretical principles and practices would achieve better results than one that was not. The split into two areas: (1) building the multi-sided keystone platform and (2) building the dealmaking application both with modules and attributes to enable health and performance monitoring worked well.

Building the platform worked well. Companies (modeled as Deal_Accounts) are associated with platform sides in the final package. There was significant discussion about whether it should be the platform members (Deal_Delegates) that should be associated with the sides instead of having their associated companies associated with the sides. This is an easy to implement option. It requires two relationship changes. In some cases, a member can belong to more than one company, or they can change companies. These options are supported as well. Building the deal-making process in Sugar proved to be a challenge as there was less guidance from previous examples to follow. Linking Deal_Delegates into Deals was a crucial problem to be solved and took time. Sugar did not directly support association objects so, as described above in the prototyping stage output, an alternative implementation had to be worked out. The deal application control was built in Django by another team. This was good to enable a lot of customization in the UI and decouple 
that work from Sugar. The process control, workflow, did not have to be implemented in Sugar, but the application in Django had to use the Sugar APIs and this took more effort than expected. It was also hard to keep the sugar component in sync with the Django application and at the end there was a lot of integration work to be done. In hindsight it would have been better to have someone else work on this separately and iron out the details early rather than doing it at the end.

The final version for production was one that had no major problems and all of the basic functionality required was there. It was a model which served as a general framework from which specialized keystones for making money could be customized. The modules were built with attributes which could be monitored and tracked for performance. Reporting tools would have to be built according what was required to measure and assess the health of the platform and productivity of members either alone or in groups from deal-making activities. It's possible to measure the following to help the keystone owner govern and regulate the platform:

1) Deal Data

a) The number, size, and types of Deals made over time.

b) The closure rate, time to reach each deal state, and get agreement on each dimension.

c) Deal issue tracking: The number and kinds of issues raised on dimensions, their solution rate, and improvement on deal outcomes.

\section{2) Deal Group Data}

a) The amount of successes and growth in deals, group interactions over time. 
b) Relationship building through deals: degree of continued deal collaborations amongst deal group participants between members building their capabilities and experience for future deals over time.

\section{3) Keystone Ecosystem Member Data}

a) The frequency of deals per member, per side.

b) Earnings per member: monetary earnings over time.

c) Growth and development through deal making activities, relationships with members and groups, growth in capabilities, skills and knowledge.

d) Rating scores as a reflection of reputation and trust, ability to do what you say you will do.

e) Commitment to the platform seen through deal activity, delivery and growth, and membership duration.

Time did not permit the development of any analytics reports though it could be done for a keystone listing the data listed above. Nor was it possible to develop a MashUp to get real-time business analytics similar to reports which get statistical data over larger intervals of time. The JackBe Presto product was considered to be a good candidate Web App and MashUp development tool that could be used but it was not necessary for this research. It should work through use of the Sugar APIs. 


\section{Chapter 6. Conclusion, Limitations, Suggestions for Future Research}

\subsection{Conclusion}

A software system that supports a multi-sided platform keystone ecosystem for making money does not appear to have been implemented. Based on a CRM with functionality to support relationship management and common business processes, the implementation of the software system to support a MSP keystone ecosystem provides capabilities to grow the revenue for the keystone ecosystem and its members. As Iansiti \& Levien (2004) attest, the relationships in a keystone are most important for its operation and they affect the health of each member and the entire ecosystem. The solution provided in this research supports relationship management for a keystone ecosystem - not only with customers but between members on all sides of the platform interconnected through dealmaking activities for their livelihood. The platform tools enable the keystone owner to monitor and manage the health of the ecosystem and ensure everyone does well in terms of revenue growth through deal opportunities.

The Open Source Community Edition of SugarCRM (SugarCE) was used to construct a multi-sided platform to support a keystone company that can generate revenue through deal-making. It therefore takes advantage of open source development for community support and participation and low development cost. The SugarCRM package that was created in this research can be installed into instances of Sugar with little impact on the existing Sugar application. There are Sugar platform tools to allow easy customizations to suit different types of keystones. 
One size does not fit all and that is taken into account with this research. Any keystone would require customization according to the steps used to build the keystone (Bailetti 2010). The modules in the package were designed to enable this to be easily done and mostly by setting attribute values in the modules although new modules could be created as well. Value exists in being able to monitor and maintain the health of the keystone. This is a major part of the "Keystone Advantage" described well by Iansiti \& Levien (2004). Being able to measure it and make adjustments dynamically based on feedback is supported by software from this research.

The kind of deals in the keystone ecosystem depends on the kind of keystone ecosystem it is. The kind of keystone ecosystem relates to the kinds of resources, capabilities and assets members bring to it and how they organize themselves to produce products and services together in deals with customers. It is believed that principles from such areas as the Resource Based Theory, dynamic capabilities, and stakeholder analysis and management, provide potential for value creation and productivity for members and these theoretical areas have a sound basis from application in traditional firms. Using them for a multi-sided keystone ecosystem therefore adds higher probability of success. In traditional hierarchical firms there is a high cost for coordination of activities. In a keystone ecosystem there is no hierarchical control. They have flat and open architectures. In keystone ecosystems enabled for making money through deals, members can easily and efficiently self-organize using their capabilities and resources to make collaborative deals.

Members of a keystone ecosystem make money collaborating and co-creating value in multi-sided deals. Customers are members of the ecosystem and members have the 
advantage of extended reach and easy access with each other for collaborative deals with their customers. The health of the keystone is measured through feedback on dealmaking activity. Productivity and growth of the members is indicative of health and it is measured through value gained from deal participation. Part of that value is monetary, and another is capability development to enable future deals.

Using a CRM framework is practical since it enables business processes to be supported in a keystone ecosystem as it does for traditional single-sided companies. There is a systematic way to design, provision, and manage a keystone ecosystem for making money, and the process for deal-making is a way for keystone ecosystem members to make money and grow together. To date, keystone ecosystems have not provided enablement for deal making to affiliated members. I believe this research provides a first step towards that goal.

The keystones (of a keystone ecosystem) have a significant role to sustain the ecosystem. This research offers an approach which uses principles and rules from well-established theory to support that strategic role. The software product from this research takes this this theory into account and applies it in the architectural design of the system of components. It enables tools which can use data from processes using the components to support the operations and strategic management of the keystone ecosystem and measure its health. Most descriptions of keystone ecosystems are described with analogies to natural ecosystems as guidance to how they should operate and what possibilities exist for business ecosystems. This research makes a practical extension to that vision by providing practical minimum value product for managing a keystone ecosystem enabled to make money through deals. It will help members make more revenue generating 
deals, close deals faster with extended customer reach and with the support of a stronger platform of resources and capabilities than they could on their own.

\subsection{Limitations and Opportunities for Future Research}

The output of this research offers opportunities for improvement, extensions, and evolution. It only provides a minimal value platform. Customization is expected to be done for any real application.

Trials should be done and case studies performed to assess the usefulness of the software application to support keystone ecosystems for making money.

The software produced by this research is very basic by intent. Any new installation will require work to define and build the keystone. The model $\mathrm{C}$ business model from a multi-sided platform keystone ecosystem must be well understood and communicated to all members planning to join. Understanding the basics of MSPs and keystone ecosystems and the potential they offer are prerequisites which must be learned. Building an organization is not easy and one goal is to see how well it works to systematically build a keystone for making money and with the tools provided from this research to support it.

If Sugar is used as a standalone application to support a multi-sided platform keystone ecosystem, then security needs to be implemented. There is at least one plug-in in SugarForge to support groups. Each group has access privileges that can be specified for different modules. Access to fields of different modules could be restricted to groups of users or specific users.

The User Interface, its customization and styling, has not been explored. To date, there are only two templates offered for the community edition of SugarCRM. 
Many companies use a Content Management System (CMS) for their online web-site. It is now possible to integrate Drupal with SugarCRM ${ }^{\mathrm{v}}$. It would be interesting to integrate the Sugar app with a CMS, such as Drupal, to support a keystone.

Integration with social networking sites such as LinkedIn and Facebook and Twitter offers more opportunities. Sugar provides a connector to LinkedIn and it can be used as a basis for developing connectors to other sites.

Move varieties of tools for interaction and collaboration should be used or developed.

Possibilities include web-conferencing systems with video, chat, whiteboards, and document sharing. The use of online deal meetings using the BigBlueButton ${ }^{\mathrm{vi}}$ webconferencing system where documents can be presented and shared and saved as part of the deal would be good to develop. Other possibilities are forums for discussion and chat. SugarForge also has many packages that could be added as complements to the platform.

Analytical Reports have not been done but real-time business intelligence would be a good complement to the platform. A MashUp or a web-app for real-time analytics or a deal dashboard could be made.

The incorporation of different theoretical constructs for building and managing a keystone organization should be tried. Different types of keystones may be more manageable from a different approach and theoretical perspective.

Develop better mechanisms to observe and track capability development and asset management for the keystone, its members, and groups. It's important to see how capabilities and opportunities grow with the keystone advantage.

Develop better mechanisms to manage deal-groups, their evolution and interactions. 
If there is a side of investors which may include venture capitalists, it would be good to develop an investment stake that investors can create as an investment in a company started by an entrepreneur. An investment may be managed as a kind of deal between an investor and a company. Data structures and attributes should be created to track growth through the various stages of development and the typical VC investment stages. 


\title{
Appendices
}

\author{
Appendix A
}

\section{A.1 Business Models $A$ and $C$ for Revenue Growth}

Bailetti 2010 gives the following diagrams for a traditional company/firm revenue generating model referred to as "model A", and an ecosystem revenue model referred to as "model C". In the model A approach, suppliers sell directly to customers or through intermediaries. Traditional Customer Relationship Management (CRM) processes and tools are used to drive sales and marketing. In the model $\mathrm{C}$ approach, used in a keystone, we have sides with groups of members with complementary resources, assets, capabilities, etc. which they bring to the platform. The keystone offers the advantage of collaboration between members to offer products, services, and solutions of greater variety for customers and opportunities for members. We see network effects of attraction between sides and members because of complementarities. 


\section{$\begin{array}{ll}\text { A. Traditional } & \text { B. Ecosystem }\end{array}$}

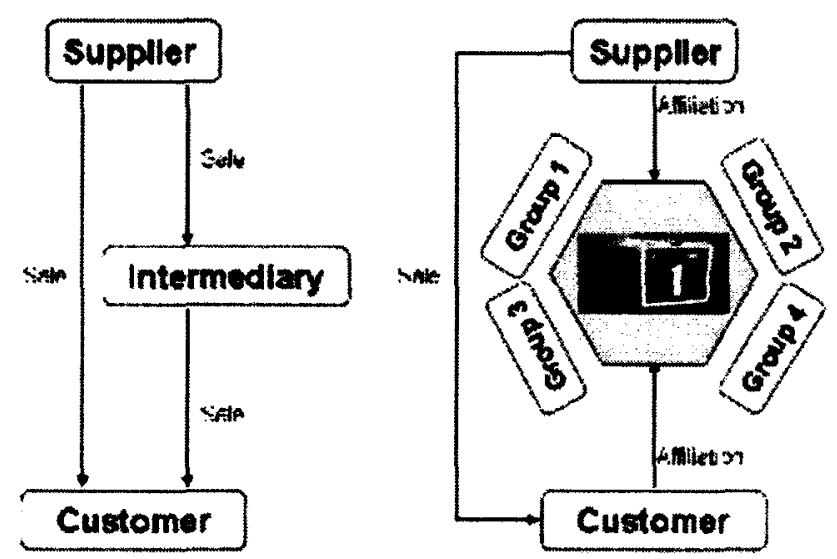

Figure 7 - Traditional 'model A' versus Keystone 'model C' Business Models

Appendix B

\section{B.1 Bugs and Issues from testing the last two prototypes}

A list of problems which were seen when testing the last two versions of the product are listed below. Note: Version 0.4 was a re-write and hence the names of some modules had changed. Version 0.4 became the final prototype deemed satisfactory for use.

v0.3 Results:

1. Fix one-to-many relationships. -- lower in priority since we can create, navigate, edit, delete using the sub-panels on the various Modules. 
2. Deal 'Assigned To' field doesn't work and should be removed from the vardefs, Popup viewdefs. Same as what is done for DealStakes and the assigned fields which should not have been put in there. -- High priority - Fixed using Studio. Does not appear in version 6.1 .0 of Sugar.

3. Many-to-many relationship for Deals to Documents: manually select Document for the Deal after creation.

Can create a Document by itself but have to clear the Deals links. Problem fixed by going into Studio and removing the extra links on the Documents module.

4. Problem with 'Assigned To' field pop-up not updating the field when a Deal is selected. -- high priority.

5. Assigning Stakes to MADaccounts: select from the Account but pop-up only lists type of stake, not the name. Must create the Stake from the Account. -- High priority

6. Voting Decision option for "Undecided/Blank", the default when doling them out. -- fixed

7. For Association Classes: - need Report to list all Deals, Stakeholder Accounts.

8. Too hard to navigate through the Deal Stakes: - need Report to list Stakeholder Accounts related to Dimensions through the Votes.

9. Listview updates to show more information. -- low priority

10. Cannot reset password because of mail settings. -- Fixed

11. Problem with DealVotes having the 'Assigned To' fields. -- fixed in next version 0.4 
V0.4 Results:

1. Creating DealAccounts, Pop-up selection for Side does not automatically put the selection into the field. Typing it in works fine. This happens in other pop-up selections when creating instances of other types of modules too. Best to Create the DealAccounts, then go to the PlatformSide and Select it from there. That popup works after th DealAccount exists.

2. Increase MaxMembers on a Side. 100 is too small.

3. Deals ListView not listing the Deals. Can access by Dashlet View on homepage or through Stakes or other objects linked to the Deal. Serious problem seems to work if the Title is the same as the Name.

4. Objectives Dimension Popup search does not list the Name to select by. Listview does not work either. Dashlet view works on the homepage.

*** Serious problem -- hard to link the Objectives Dimension to the Deal.

5. Dimension number needed in the Detail View of the Additional Dimension.

6. Dashlet view for Additional Dimension shows nothing! Cannot update the Dashlets in ModuleBuilder for failure to load a file when trying to save the changes.* minor problem, not blocking.

7. Issue: SugarCRM does not automatically advance the gate when voting has passed for all dimensions for a gate. This is in the UI which implies the UI has to update the gate on the Deal. Sugar also does not know which dimensions are associated with which gates. This can be put in later as well as the gate advancement. Voting collection and tallying for a dimension is not in the Sugar Vote either. 


\section{References}

Aggarwal, V. A., Siggelkow, N., Singh, H. 2011. Governing Collaborative Activity: Interdependence and the Impact of Coordination and Exploration, Strategic Management Journal, 32: 705-730.

Aghiona, P., David, P. A., Foraye, D. 2009. Science, technology and innovation for economic growth: Linking policy research and practice in 'STIG Systems', Research Policy, 38, 681-693.

Arend, R. 2009. Reputation for Cooperation: Contingent Benefits in Alliance Activity, Strategic Management Journal, 30: 371-385.

Argyres, N. S., Felin, T., Foss, N., Zenger, T. 2012. The Organizational Economics of Organizational Capability and Heterogeneity: A Research Agenda, Social Science

Research Network, February, 2012. http://ssrn.com/abstract=2024937

Axelrod, R. 1980. More Effective Choice in the Prisoner's Dilemma, Journal of Conflict

Resolution, 24(3): 379-403.

Axelrod, R., Dion, D. 1988. The Further Evolution of Cooperation, Science, 242(4884):

1385-1390.

Allen, S., Bailetti, T., Tanev, S. 2009. Components of Co-creation, TIM Review, November. http://timreview.ca/article/301.

Bailetti, T. 2010. Blueprint and Approach to Grow Revenue in Small Technology

Companies, TIM Review, June, http://timreview.ca/article/355.

Bain, M. A. 2007. SugarCRM Developers Manual: Customize and Extend SugarCRM, Packt Publishing Ltd. http://packtpub.com 
Band, W. 2012. The Forrester Wave ${ }^{\mathrm{TM}}$ : CRM Suites for Midsize Organizations, Q3 2012, Forrester Research, Inc., Q3, July.

http://www.forrester.com/The+Forrester+Wave+CRM+Suites+For+Midsize+Organizatio ns+Q3+2012/fulltext/-/E-RES61645, free copy from SugarCRM available at

http://www.sugarcrm.com/newspress/sugarcrm-positioned-leader-independent-researchfirm

Barney, J. B. 1986. Strategic Factor Markets: Expectations, Luck, and Business Strategy, Management Science, 32(10): 1231-1241.

Barney, J. B. 1991. Firm Resources and Sustained Competitive Advantage, Journal of Marketing, 17(1): 99-120.

Barney, J., Fiet, J. O., Busenitz, L. W., Moesel, D. D. 1996. The Substitution of Bonding for Monitoring in Venture Capitalist Relations with High Technology Enterprises, Journal of High Technology Management Research, 7(1): 91-105.

Boudreau, K.J., Haigu, A. 2009. Platform rules: Multi-sided Platforms as Regulators, A. Gawer, ed. Platforms, Markets and Innovation: 163-191. Edward Elgar, London. http://www.kevinboudreau.com/papers.

Boudreau, K.J. 2008. Too Many Complementors?. Social Science Research Network, http://ssrn.com/abstract=943088, 1-37.

Boulding, W., Staelin, R., Ehret, M., Johnston, W. J. 2005. A Customer Relationship Management Roadmap: What is Known, Potential Pitfalls, and Where to Go, Journal of Marketing, 69(October): 155-166.

Brandenburger, A. M., Nailbuff, B. 1998. Co-opetition: A revolutionary mindset that combines competition with cooperation, London, Harper Collins Business 
Cable, D. M., Shane, S. 1997. A Prisoner's Dilemma Approach to Entrepreneur-Venture Capitalist Relationships, Academy of Management Review, 22(1): 142-176.

Chesbrough, H.W., 2003. The Era of Open Innovation, MIT Sloan Management Review, Spring: 2003, 35-41.

Chesbrough, H.W., Appleyard, M.M. 2007. Open Innovation and Strategy, California Management Review, 50(1): 57-76.

Clarkson, J.B.E. 1995. A Stakeholder Framework for Analyzing and Evaluating Corporate Social Performance, Academy of Management Review, 20(1): 92-117.

Coff, R. W. 2010. The Coevolution of Rent Appropriation and Capability Development, Strategic Management Journal, 31: 711-733.

Denyer, D., Tranfield, D., van Aken, J. E. 2008 Developing Design Propositions through Research Synthesis, Organization Studies, 29(03): 393-413.

Ennen, E., Richter, A. 2010. The Whole Is More Than the Sum of Its Parts-Or Is It? A Review of the Empirical Literature on Complementarities in Organizations, Journal of Management, 36(1): 207-233.

Evans, P., Wolf, B. 2005. Collaboration Rules, Harvard Business Review, July-August: 96-104.

Freeman, R. E. 1984. Strategic management: A stakeholder approach. Boston: Pitman. Gawer, A., Henderson, R. 2007. Platform Owner Entry and Innovation in Complementary markets: Evidence from Intel, Journal of Economics and Management Strategy, 16(1): 1-34. 
Gnyawali, D. R., He, J., Madhavan, R. 2006. Impact of Co-Opetition on Firm Competitive Behavior: An Empirical Examination, Journal of Management, 32(4): 507 530.

Grönroos, C. 2011. Value co-creation in service logic: A critical analysis, Marketing Theory, 11(3): 279-301.

Hagiu, A. 2007. Merchant or Two-Sided Platform?, Review of Network Economics, 6(2), http://www.people.hbs.edu/ahagiu/Merchants\%20vs\%20Two-

Sided $\% 20$ Platforms $\% 20$ for $\% 20$ RNE $\% 2006302007 \% 20$ final.pdf.

Hagiu, A., Wright, J. 2011. Multi-Sided Platforms, HBS Working Paper Number: 12024, http://hbswk.hbs.edu/item/6681.html.

Helfat, C. E., Peteraf, M. A. 2003. The Dynamic Resource-Based View: Capability Lifecycles, Strategic Management Journal, 24: 997-1010.

Iansiti, M., Levien, R. 2004a. Strategy as Ecology, Harvard Business Review, March issue: $1-11$, http://hbr.org/2004/03/strategy-as-ecology/ar/1. Iansiti, M., Levien, R. 2004b. Keystones and Dominators: Framing Operating and Technology Strategy in a Business Ecosystem, unpublished, available at http://keystonestrategy.com/publications/pdf/Ecosystems.pdf, http://www.hbs.edu/units/tom/seminars/2002/Marco_Nov_2002.pdf. Katz, M. L., Shapiro, C. 1985. Network Externalities, Competition, and Compatibility, American Economic Review, 75(3): 424-440.

Lado, A. A., Boyd, N. G., Hanlon, S. C. 1997. Competition, Cooperation, and the Search for Economic Rents: A Syncretic Model, Academy of Management Review, 22(1): 110141. 
Liebowitz, S. J., Margolis, S. E. 1994 Network Externality: An Uncommon Tragedy, The Journal of Economic Perspectives, 8(2): 133-150.

Liebowitz, S.J., Margolis, S. E. ___ Network Externalities (Effects), unpublished, University of Texas, Dallas, http://www.utdallas.edu/ liebowit/palgrave/network.html. Liebowitz, S. J., Margolis, S. E. 1994. Network Externality: An Uncommon Tragedy, The Journal of Economic Perspectives, 8(2): 133-150.

Magaña, A., Whitehead, M. 2010. Implementing SugarCRM 5.x: Install, configure, and administer a robust Customer Relationship Management system using SugarCRM.

Packt Publishing Ltd. http://www.packtpub.com/

Maklan, S., Knox, S., 2009, Dynamic capabilities: The Missing link in CRM investments, Journal of Marketing, 43 (11/12): 1392-1410.

Mertic, J. 2009. The Definitive Guide to SugarCRM: Better Business Applications. Apress. http://apress.com Mitchell, R., Agle, B., Wood, D. 1997. Toward a Theory of Stakeholder Identification and Salience: Defining the Principle of Who and What Really Counts, Academy of Management Review, 22(4): 853-886.

Nwankwo, S., Richardson, B. 1996. Organizational leaders as political strategists: a stakeholder management perspective, Management Decision, 34(10): 43-49.

Peteraf, M. A., 1993. The Cornerstones of Competitive Advantage: A Resource-Based View, Strategic Management Journal, 14(3): 179-191.

Payne, A., Frow, P., 2005. A Strategic Framework for Customer Relationship Management, Journal of Marketing, 69 (10): 167-176. 
Payne, A., Ballantyne, D., Christopher, M. 2005. A stakeholder approach to relationship marketing strategy: The development and use of the "six markets" model, European Journal of Marketing, 39 (7/8): 855-871.

Payne, A. F., Storbacka, K., Frow, P. 2008. Managing the Co-Creation of Value, Academy of Marketing Science, 36:83-96.

Peelen, E., van Montfort, K., Beltman, R., Klerkx, A. 2009. An empirical study into the foundations of CRM success, Journal of Strategic Marketing, 17(6): 453-471.

Pisano, G. P., Verganti, R. 2008. Which Kind of Collaboration Is Right for You?, Harvard Business Review, December, http://hbr.org/2008/12/which-kind-ofcollaboration-is-right-for-you/ar/1 .

Reimann, M., Schilke, O., Thomas, J.S., 2010. Customer relationship management and firm performance: the mediating role of business strategy, Academy of Marketing Science, $38: 326-346$.

Romme, A. G. L., Endenberg, G. 2006. Construction Principles and Design Rules in the Case of Circular Design, Organization Science, 17(2): 287-297.

Rochet, J-C., Tirole, J. 2003. Platform Competition In two-sided Markets, Journal of the European Economic Association, 1(4): 990-1029.

Rochet, J-C., Tirole, J. 2006 Two-sided markets: A progress report, The Rand Journal of Economics, 37(3): 645-667.

Rowley, T. J. 1997. Moving beyond Dyadic Ties: A Network Theory of Stakeholder Influences, Academy of Management Review, 22(4): 887-910.

Siggelkow, N. 2001. Change in the Presence of Fit: The Rise, the Fall, and the Renaissance of Liz Claiborne, Academy of Management Journal, 44: 838-57. 
Siggelkow, N., Rivkin, J.W. 2005. Speed and Search: Designing Organizations for Turbulence and Complexity, Organization Science, 16(2): 101-122.

Siggelkow, N. 2011. Firms as Systems of Interdependent Choices, Journal of Management Studies, 48(5): 1126-1140.

Sirmon, D. G., Hitt, H. A., Ireland, R. D., Gilbert, B. A. 2011. Resource Orchestration to Create Competitive Advantage: Breadth, Depth, and Life Cycle Effects, Journal of Management, 37(5): 1390-1412.

SugarCRM Inc., 2012. Sugar Community Edition 6.0 Documentation, SugarCRM Inc. http://developers.sugarcrm.com/documentation.php?edition= $\mathrm{OS} \& \mathrm{v}=6.0 \&$ showall=n Sull, D.N., Spinosa, C., 2005. Using Commitments to Manage across Units, MIT Sloan Management Review, Fall: 73-81.

Sun, M., Tse, E., 2009. The Resource-Based View of Competitive Advantage in TwoSided Markets, Journal of Management Studies, 46(1): 46-64.

Teece, D. J., Pisano, G., Shuen, A. 1997. Dynamic Capabilities and Strategic Management, Strategic Management Journal, 18(7): 509-533.

Teece, D. 2007. Explicating Dynamic Capabilities: The Nature and Microfoundations of (Sustainable) Enterprise Performance, Strategic Management Journal, 28, 1319-1350. van Aken, J. E. 2004. Management Research Based on the Paradigm of the Design Sciences: the Quest for Field-Tested and Grounded Technological Rules, Journal of Management Studies, 41 (2): 219-246.

Wan, W. P., Hoskisson, R. E., Short, J. C., Yiu, D. W. 2011. Resource-Based Theory and Corporate Diversification: Accomplishments and Opportunities, Special Issue: Twenty years of Resource-Based Theory, Journal of Management, 37(5): 1335-1368. 
Weiss, M. 2010. Keystone: Adjective or Noun?, TIM Review, September, http://timreview.ca/article/376.

Wernerfelt, B. 1984. A Resource-based View of the Firm, Strategic Management Journal, 5(2): 171-180.

Williamson, O. E. 2009. Pragmatic methodology: a sketch, with applications to transaction cost economics, Journal of Economic Methodology, 16(2): 145-157.

Winter, S. G. 2003. Understanding Dynamic Capabilities, Strategic Management

Journal, 24: 991-995.

Yoffie, D. B., Kwak, M. 2006. With Friends like These: The Art of Managing Complementors, Harvard Business Review, September, http://hbr.org/2006/09/withfriends-like-these-the-art-of-managing-complementors/ar/1.

Zollo, M., Winter, S. G. 2002. Deliberate Learning and the Evolution of Dynamic Capabilities, Organization Science, 13(3): 339-351.

\footnotetext{
${ }^{i}$ See http://opensource.org/licenses/category for categorization and description of the open source public licenses.

ii Extension packages for the Sugar Community go to the' SugarForge' at sugarforge.org.

iii See information about Channeltivity at http://www.channeltivity.com/

iv See information about RelayWare is at http://www.relayware.com/ or at http://www.crunchbase.com/company/relayware

` See Drupal - SugarCRM Integration at http://www.drupalcube.com/drupal-sugarcrm-Integration

${ }^{v i}$ See BigBlueButton at http://bigbluebutton.org
} 